\title{
Importance of Entropy in the Conformational Equilibrium of Phenylalanine: A Matrix-Isolation Infrared Spectroscopy and Density Functional Theory Study
}

\author{
A. Kaczor, ${ }^{\dagger,+, \#}$ I. D. Reva, ${ }^{\dagger, \#}$ L. M. Proniewicz, $, \$, \#$ and R. Fausto ${ }^{*, \dagger, \#}$ \\ Department of Chemistry, University of Coimbra, P-3004-535 Coimbra, Portugal, Faculty of Chemistry, \\ Jagiellonian University, Ingardena 3, 30-060 Krakow, Poland, and Regional Laboratory of Physicochemical \\ Analysis and Structural Research, Jagiellonian University, Ingardena 3, 30-060 Krakow, Poland
}

Received: September 8, 2005; In Final Form: December 16, 2005

\begin{abstract}
The conformational behavior and infrared spectrum of L-phenylalanine were studied by matrix-isolation infrared spectroscopy and DFT [B3LYP/6-311++G(d,p)] calculations. The fourteen most stable structures were predicted to differ in energy by less than $10 \mathrm{~kJ} \mathrm{~mol}^{-1}$, eight of them with abundances higher than $5 \%$ at the temperature of evaporation of the compound $(423 \mathrm{~K})$. Experimental results suggest that six conformers contribute to the spectrum of the isolated compound, whereas two conformers ( $\mathrm{IIb}_{3}$ and $\mathrm{IIIb}_{3}$ ) relax in matrix to a more stable form $\left(\mathrm{IIb}_{2}\right)$ due to low energy barriers for conformational isomerization (conformational cooling). The two lowest-energy conformers ( $\mathrm{Ib}_{1}$, Ia) differ only in the arrangement of the amino acid group relative to the phenyl ring; they exhibit a relatively strong stabilizing intramolecular hydrogen bond of the $\mathrm{O}-\mathrm{H} \cdots \mathrm{N}$ type and the carboxylic group in the trans configuration $\left(\mathrm{O}=\mathrm{C}-\mathrm{O}-\mathrm{H}\right.$ dihedral angle ca. $\left.180^{\circ}\right)$. Type II conformers have a weaker $\mathrm{H}$-bond of the $\mathrm{N}-\mathrm{H} \cdots \mathrm{O}=\mathrm{C}$ type, but they bear the more favorable cis arrangement of the carboxylic group. Being considerably more flexible, type II conformers are stabilized by entropy and the relative abundances of two conformers of this type $\left(\mathrm{IIb}_{2}\right.$ and $\left.\mathrm{IIc}_{1}\right)$ are shown to significantly increase with temperature due to entropic stabilization. At $423 \mathrm{~K}$, these conformers are found to be the first and third most abundant species present in the conformational equilibrium, with relative populations of ca. $15 \%$ each, whereas their populations could be expected to be only ca. 5\% if entropy effects were not taken into consideration. Indeed, phenylalanine can be considered a notable example of a molecule where entropy plays an essential role in determining the relative abundance of the possible low-energy conformational states and then, the thermodynamics of the compound, even at moderate temperatures. Upon UV irradiation $(\lambda>235 \mathrm{~nm})$ of the matrix-isolated compound, unimolecular photodecomposition of phenylalanine is observed with production of $\mathrm{CO}_{2}$ and phenethylamine.
\end{abstract}

\section{Introduction}

Amino acids constitute one of the most important families of compounds because they are the basis of polypeptide and protein chains and take part in many fundamental biochemical processes, like, for instance, enzymatic catalysis and neurotransmission. In proteins, amino acids occur as residues of neutral L- $\alpha$ forms, whereas the zwitterionic structures are found in the crystalline state and in solution. ${ }^{1-3}$ Amino acids adopt their neutral form also in the gas phase $\mathrm{e}^{4-13}$ and in low-temperature inert matrixes. ${ }^{14-28}$ Therefore, the structures of these compounds have been extensively studied in both these media. A number of aliphatic amino acids as well as some of their derivatives have been investigated experimentally up to date: glycine, $,, 5,14-18$ sarcosine $(N$-methylglycine $),{ }^{19} N, N$-dimethylglycine, ${ }^{20}$ alanine, ${ }^{6,21-23}$ valine, ${ }^{7,24}$ proline ${ }^{8,25,26}$ and serine..$^{27,28}$ Most of these studies also reported theoretical calculations at various levels of theory. ${ }^{5-13,15,17,19-28}$

In general, the gas-phase results are qualitatively consistent with the matrix-isolation data, despite van der Waals forces

\footnotetext{
* Corresponding author. E-mail: rfausto@ci.uc.pt.

$\dagger$ University of Coimbra.

$\stackrel{+}{*}$ Faculty of Chemistry, Jagiellonian University.

$\S$ Regional Laboratory of Physicochemical Analysis and Structural Research, Jagiellonian University.

\#E-mail: A.K., kaczor@chemia.uj.edu.pl; I.D.R., reva@qui.uc.pt; L.M.P., proniewi@chemia.uj.edu.pl.
}

appearing in the solid matrix between the sample and inner gas molecules. The most stable structures of aliphatic amino acids have been found to be stabilized by a bifurcated H-bond linking the carboxylic oxygen atom and the hydrogen atoms of the amino group. However, existence of other conformers has been proven experimentally for all molecules studied hitherto. ${ }^{4-13,15-18,21-28}$

The conformational distribution of amino acids depends strongly on the experimental conditions, because they have low conformational interconversion barriers. Low barriers have been predicted theoretically for glycine and alanine (for alanine, as low as $129 \mathrm{~cm}^{-1}$ and less than $35 \mathrm{~cm}^{-1}$ for the internal rotations around $\mathrm{C}-\mathrm{N}$ and $\mathrm{C}-\mathrm{C}(=\mathrm{O})$ bonds, respectively). ${ }^{5}$ Indeed, conformer interconversion in glycine has been observed experimentally by matrix-isolation IR spectroscopy ${ }^{15-17}$ to take place at a temperature as low as $13 \mathrm{~K}$ : annealing at this temperature of an argon matrix containing the three experimentally observable conformers of the compound led to conversion of the conformer bearing the $\mathrm{N}-\mathrm{H} \cdots \mathrm{O}-\mathrm{H}$ bond into the most stable form. ${ }^{15,17}$ Hence, to predict possible conformational interconversion processes, estimating the energy barriers between conformers is strictly necessary. DFT methods have been shown to be reliable enough to provide good estimations of energy barriers for this kind of molecules, being successfully used in the past, for instance, in the investigation of serine, ${ }^{27}$ valine $^{24}$ and glycine derivatives. ${ }^{19,20}$ 
Contrary to aliphatic amino acids, the structures and preferred conformations of aromatic amino acids are still quite unexplored fields. There are three naturally occurring aromatic amino acids: phenylalanine (Phe), tyrosine (Tyr) and tryptophan (Trp). Due to the presence of UV chromophores in their structures, these compounds have been extensively studied in the gaseous phase by laser spectroscopy..$^{9,11,12,29-32}$ However, according to our best knowledge, only two studies have been reported until now, which investigated the fingerprint region of the IR spectra of these compounds (Trp and Phe) in the gaseous phase. ${ }^{31,33}$ For Phe, the IR spectrum was recorded, ${ }^{33}$ but the experimental approach used was not conformationally selective. Moreover, for interpretation of the experimental results, the authors took into consideration theoretical results for a single conformer (and by far not the lowest-energy one), only. For Trp, three conformers could be characterized by IR ion-dip spectroscopy and DFT calculations. ${ }^{31}$

Phe and Trp were also studied previously in a supersonic beam by UV and IR ion-dip spectroscopy combined with ab initio computations, by Snoek et al., ${ }^{9,12}$ These studies centered on the analysis of the $\mathrm{O}-\mathrm{H}$ and $\mathrm{N}-\mathrm{H}$ stretching vibrations, and an extensive computational analysis was presented. Six conformers of each compound were found to contribute to the corresponding UV-UV hole-burning spectra, whereas five and six conformers were recognized in the ion-dip IR spectra of Phe and Trp, respectively. ${ }^{9,12}$ The assignment of one of the lowpopulated Phe conformers was later revised by Lee et al., ${ }^{32}$ who studied hydration processes of Phe with the combined use of the R2PI method and quantum-chemical calculations. More recently, ultraviolet rotational contour analysis studies brought a new assignment of Phe conformers. ${ }^{11}$

Despite the important discrepancies found in the different studies previously reported, $,, 11,12,31$ there is nowadays a general consensus relative to the fact that the most stable conformer in both Phe and Trp is stabilized by a relatively strong intramolecular H-bond established between the carboxylic $\mathrm{OH}$ group and the nitrogen atom. The increased stability of this conformer, compared to what is found for aliphatic amino acids, was explained by the existence of a "daisy-chain" sequence of interactions involving aromatic $\pi$-electrons, the amino group and the carboxylic $\mathrm{OH}$ group. ${ }^{9}$ The same lowest-energy conformer was postulated in a recent study of matrix-isolated tyrosine, by Ramaekers et al. ${ }^{34}$ These authors considered the contribution from nine conformers, with three types of the $\mathrm{H}$-bonds, to the recorded matrix-isolation IR spectra. Nevertheless, they were not able to distinguish between conformers, which have the same $\mathrm{H}$-bond type.

In light of controversies concerning the structure of Phe, matrix-isolation IR spectroscopy appeared as a promising technique to investigate the conformational preferences of the compound. Thus, this technique was used as the main research tool in this study. Interpretation of the experimental data received support from extensive high-level DFT calculations, which provided geometries and conformer relative energies, normal modes and conformational interconversion energy barriers. As will become clear in this work, investigation of possible interconversion processes and consideration of entropy effects in calculating the relative abundance of conformers in the gaseous phase proved to be key factors in the proper description of the experimental data.

\section{Methods}

2.1. Experimental Methods. L-Phenylalanine (purity $\geq 99.0 \%$ ) was purchased from Merck Sp. z o.o. (Warsaw, Poland) and used without further purification.
FT-IR spectra were recorded in the $400-4000 \mathrm{~cm}^{-1}$ range using a Mattson Infinity 60AR series FT-IR spectrometer, with $0.5 \mathrm{~cm}^{-1}$ resolution. The sample was co-deposited with argon isolant gas (99.9999\%, Air Liquide) onto a cryogenically cooled CsI window. The selected temperature of the optical substrate $(12 \mathrm{~K})$ was obtained using an APD Cryogenics closed-cycle helium refrigeration system with a DE-202A expander. The temperature was measured directly at the sample holder by a silicon diode temperature sensor, connected to a digital controller (Scientific Instruments, Model 9650-1), with accuracy of 0.1 $\mathrm{K}$. Annealing of the matrixes was performed by increasing the temperature gradually up to $33 \mathrm{~K}$. Spectra of the annealed matrix were recorded without subsequent cooling cycle.

A $150 \mathrm{~W}$ xenon arc lamp (Osram XBO 150W/CR OFR) was used for photolysis of the matrix through the outer $\mathrm{KBr}$ window of cryostat $(\lambda>235 \mathrm{~nm})$.

In the previous studies of matrix-isolated glycine, alanine and valine, ${ }^{17,22,24}$ it was found that these amino acids tend to decompose at strong heating. Thus, sublimation temperature had to be kept as low as possible to avoid decomposition of the compounds, but high enough to allow their sublimation. Sublimation temperatures around $150-160{ }^{\circ} \mathrm{C}$ were found to satisfy these conditions for the above listed amino acids with aliphatic side chains. The same deposition conditions were also found in this study to be satisfactory for phenylalanine. The compound was evaporated from two different furnaces at 150 ${ }^{\circ} \mathrm{C}(423.15 \mathrm{~K})$. Deposition from a stainless steel Knudsen cell catalyzed decomposition of the compound, as evidenced by the appearance in the spectrum of the bands due to monomeric $\mathrm{CO}_{2}$ along with absorptions due to phenylalanine. Deposition from a glass furnace at the same temperature resulted in a similar spectrum of matrix-isolated phenylalanine, which was free from $\mathrm{CO}_{2}$ related bands and other decomposition products. The latter spectra were the subject of analysis in this study.

2.2. Computational Methods. To generate the structures of Phe to be provided as input geometries to the calculations, the relevant torsion angles were varied in a systematic way. Eighty structures with no significant steric hindrance were then subjected to geometry optimization and frequency calculations at the DFT level of approximation with the standard $6-31+\mathrm{G}(\mathrm{d})$ basis set. The DFT calculations were carried out with the threeparameter density functional $\mathrm{B} 3 \mathrm{LYP}^{35,36}$ and the obtained conformers were subsequently reoptimized at the B3LYP/ $6-311++G(d, p)$ level of theory. Twenty two and fourteen conformers were found to be in the 20 and $10 \mathrm{~kJ} \mathrm{~mol}^{-1}$ energy range relative to the most stable form, respectively. Vibrational spectra and thermochemical properties (at 298.15 and 423.15 $\mathrm{K})$ were computed for all calculated conformers and the relative abundances of the most stable conformers at these two temperatures were then estimated using the $\Delta G=R T \ln K_{\mathrm{c}}$ equation, where $\Delta G$ is the Gibbs free energy relative to the most stable conformer and $K_{\mathrm{c}}$ is the ratio of the concentrations of a pair of conformers.

Additionally, the transition states for conformational interconversions were computed at the B3LYP/6-311++G(d,p) level of theory, with the STQN (QST2 or QST3) method, for chosen pairs of conformers differing by internal rotation around the $\mathrm{C}_{1}-\mathrm{C}_{\alpha}, \mathrm{C}_{\alpha}-\mathrm{C}_{\beta}$, or $\mathrm{C}_{\alpha}-\mathrm{N}$ bond. The transition states between conformers differing in the conformation of the carboxylic group (cis or trans $\mathrm{O}=\mathrm{C}-\mathrm{O}-\mathrm{H}$ configuration) were not investigated systematically, because the barrier associated with the $\mathrm{C}-\mathrm{O}$ internal rotation has been shown to be high for amino acids and similar carboxylic acids, e.g., more than $5500 \mathrm{~cm}^{-1}(66 \mathrm{~kJ}$ $\mathrm{mol}^{-1}$ ) for glycine ${ }^{5}$ and $53 \mathrm{~kJ} \mathrm{~mol}^{-1}$ for glycolic acid. ${ }^{37}$ Only 
TABLE 1: Relative Energies $\left(\Delta E, \mathrm{~kJ} \mathrm{~mol}^{-1}\right.$; Including the Zero-Point Vibrational Energy), Dipole Moments ( $\mu$, Debye) and Main Dihedral Angles (deg) of the Phe Conformers within $30 \mathrm{~kJ} \mathrm{~mol}^{-1}$ Range $^{a}$

\begin{tabular}{|c|c|c|c|c|c|c|c|c|}
\hline \multicolumn{2}{|c|}{ name } & \multirow[b]{2}{*}{$\Delta E$} & \multirow[b]{2}{*}{$\mu$} & \multirow[b]{2}{*}{$\mathrm{O}=\mathrm{C}-\mathrm{O}-\mathrm{H}$} & \multirow[b]{2}{*}{$\mathrm{C}_{1}-\mathrm{C}_{\alpha}-\mathrm{C}_{\beta}-\mathrm{C}_{\gamma}$} & \multirow[b]{2}{*}{$\mathrm{C}_{1}-\mathrm{C}_{\alpha}-\mathrm{N}-l p$} & \multirow[b]{2}{*}{$\mathrm{O}=\mathrm{C}_{1}-\mathrm{C}_{\alpha}-\mathrm{N}$} & \multirow[b]{2}{*}{$\mathrm{C}_{\alpha}-\mathrm{C}_{\beta}-\mathrm{C}_{\gamma}-$ ring } \\
\hline$b$ & $c$ & & & & & & & \\
\hline $\mathrm{Ib}_{1}$ & III & 0.0 & 5.6 & -178.6 & 175.2 & 29.8 & 166.1 & 16.0 \\
\hline Ia & I & 0.2 & 5.2 & 179.2 & -74.3 & -22.2 & -170.2 & -9.1 \\
\hline $\mathrm{Ib}_{2}$ & IV & 0.5 & 5.5 & 179.2 & 170.1 & -27.2 & -167.4 & 13.8 \\
\hline $\mathrm{IIa}_{1}$ & II & 3.7 & 1.2 & 0.1 & -66.4 & -178.3 & -3.6 & 1.5 \\
\hline $\mathrm{IIb}_{1}$ & VII & 4.2 & 2.3 & -0.7 & 177.1 & -72.2 & -31.0 & 9.9 \\
\hline $\mathrm{IIb}_{2}$ & VIII & 4.5 & 1.3 & -1.1 & 163.6 & 163.1 & -21.9 & -7.3 \\
\hline $\mathrm{IIc}_{1}$ & VI & 4.7 & 1.4 & -2.1 & 61.6 & 174.0 & -56.9 & -8.7 \\
\hline $\mathrm{IIb}_{3}$ & IX & 5.0 & 1.9 & 0.2 & 174.8 & 83.4 & 12.4 & 4.7 \\
\hline $\mathrm{IIIb}_{1}$ & & 7.1 & 2.2 & 1.5 & 172.8 & 64.3 & -139.0 & 9.5 \\
\hline $\mathrm{IIIa}_{1}$ & V & 7.2 & 1.5 & 0.7 & -70.4 & -176.1 & -178.1 & -0.8 \\
\hline $\mathrm{IIIb}_{2}$ & & 7.9 & 2.6 & -1.6 & 173.1 & -58.9 & 140.6 & 11.6 \\
\hline IIIc $_{1}$ & & 8.0 & 1.5 & 0.1 & 59.0 & 179.4 & 109.2 & -12.1 \\
\hline $\mathrm{IIc}_{2}$ & & 9.0 & 1.8 & -0.9 & 62.5 & -62.3 & -56.1 & -9.5 \\
\hline $\mathrm{IIIb}_{3}$ & & 9.4 & 1.7 & 0.5 & 161.5 & 170.6 & 136.6 & -4.4 \\
\hline $\mathrm{IIa}_{2}$ & & 11.2 & 2.2 & -0.1 & -62.7 & -71.4 & -20.6 & 2.0 \\
\hline Ic & & 12.5 & 5.0 & -174.0 & 65.8 & 35.9 & 156.3 & -9.9 \\
\hline $\mathrm{IIIc}_{2}$ & & 13.1 & 2.6 & -2.0 & 59.9 & -51.2 & 119.5 & -11.6 \\
\hline Id & & 13.1 & 5.0 & 175.0 & 96.1 & -32.9 & -158.4 & 12.8 \\
\hline $\mathrm{IIIa}_{2}$ & & 13.5 & 2.1 & 0.4 & -66.0 & -58.3 & 163.4 & 0.9 \\
\hline $\mathrm{IIIc}_{3}$ & & 13.7 & 2.3 & 1.5 & 76.1 & 59.3 & -111.2 & -7.9 \\
\hline $\mathrm{IIc}_{3}$ & & 15.7 & 1.9 & 0.2 & 77.2 & 89.1 & 11.7 & -26.2 \\
\hline $\mathrm{IVc}_{1}$ & & 19.7 & 3.7 & -173.3 & 66.1 & 175.3 & -16.5 & -21.7 \\
\hline $\mathrm{IVc}_{2}$ & & 23.5 & 4.9 & -176.7 & 71.3 & 98.3 & 9.5 & -25.6 \\
\hline $\mathrm{IVa}_{1}$ & & 27.1 & 3.1 & 178.1 & -66.9 & -178.4 & -9.7 & -4.3 \\
\hline $\mathrm{IVb}_{1}$ & & 27.4 & 3.2 & 177.8 & 160.3 & 164.6 & -23.8 & -14.9 \\
\hline
\end{tabular}

a "lp" states for the lone pair of the nitrogen atom and $\left(\mathrm{C}_{1}-\mathrm{C}_{\alpha}-\mathrm{N}-\mathrm{lp}\right)$ is defined as $\left[\left(\mathrm{C}_{1}-\mathrm{C}_{\alpha}-\mathrm{N}-\mathrm{H}_{8}\right)+\left(\mathrm{C}_{1}-\mathrm{C}_{\alpha}-\mathrm{N}-\mathrm{H}_{9}\right)\right] / 2+180$. Dihedral angle " $\mathrm{C}_{\alpha}-\mathrm{C}_{\beta}-\mathrm{C}_{\gamma}-$ ring" is defined as $\left[\left(\mathrm{C}_{\alpha}-\mathrm{C}_{\beta}-\mathrm{C}_{\gamma}-\mathrm{C}_{\delta}^{\prime}\right)+\left(\mathrm{C}_{\alpha}-\mathrm{C}_{\beta}-\mathrm{C}_{\gamma}-\mathrm{C}^{\prime \prime}{ }_{\delta}\right)\right] / 2$ and designates the angle formed by the $\mathrm{C}_{\alpha}-\mathrm{C}_{\beta}$ bond with the plane perpendicular to the plane of the phenyl ring. ${ }^{b}$ Conformers $\mathrm{IVc}_{2}, \mathrm{IVa}_{1}$ and $\mathrm{IVb}_{1}$, despite having energies above $20 \mathrm{~kJ}^{\mathrm{mol}}{ }^{-1}$, are included in this table to show geometrical trends of conformers of type IV (which are systematically found to have high relative energies and for obvious reasons will not be discussed further in this article). ${ }^{c}$ Conformer nomenclature used in refs 9 and 11 .

\section{CHART 1: Atom Numbering for Phenylalanine ${ }^{a}$}

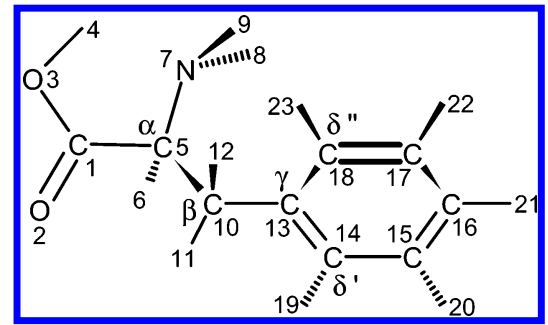

${ }^{a}$ Hydrogen atoms are presented by their numbers only and are not shown explicitly. Carbon atoms $\mathrm{C} 5, \mathrm{C} 10, \mathrm{C} 13, \mathrm{C} 14$ and $\mathrm{C} 18$ are alternatively referred in the text as $\mathrm{C}_{\alpha}, \mathrm{C}_{\beta}, \mathrm{C}_{\gamma}, \mathrm{C}_{\delta}^{\prime}$ and $\mathrm{C}^{\prime \prime}$, respectively.

one example of such barrier was calculated in this study to demonstrate that this barrier is also high for Phe.

All the above-mentioned calculations were performed using the Gaussian $98^{38}$ or Gaussian03 ${ }^{39}$ suites of programs.

Calculated harmonic frequencies obtained at the B3LYP/ $6-311++G(d, p)$ level of theory were used in the analysis of the experimental spectra. They were scaled down by the factor of 0.98 , to account mainly for anharmonicity effects and limitations of the basis set. Potential energy distributions (PED) of the normal modes were computed in terms of natural internal coordinates $^{40}$ with the Gar2ped program. ${ }^{41}$

\section{Results and Discussion}

3.1. Geometries. Chart 1 shows the molecular structure of phenylalanine monomer and atom numbering scheme adopted in this study.

The conformational multiplicity of Phe is defined by five degrees of freedom, namely by rotations around $\mathrm{C}_{1}-\mathrm{O}_{3}$ $(\mathrm{C}-\mathrm{O}) ; \mathrm{C}_{1}-\mathrm{C}_{5}\left(\mathrm{C}_{1}-\mathrm{C}_{\alpha}\right) ; \mathrm{C}_{5}-\mathrm{C}_{10}\left(\mathrm{C}_{\alpha}-\mathrm{C}_{\beta}\right) ; \mathrm{C}_{10}-\mathrm{C}_{13}\left(\mathrm{C}_{\beta}-\mathrm{C}_{\gamma}\right)$
CHART 2: Conformer Types Resulting from Different Orientations of the Amino Acid Fragment ${ }^{a}$

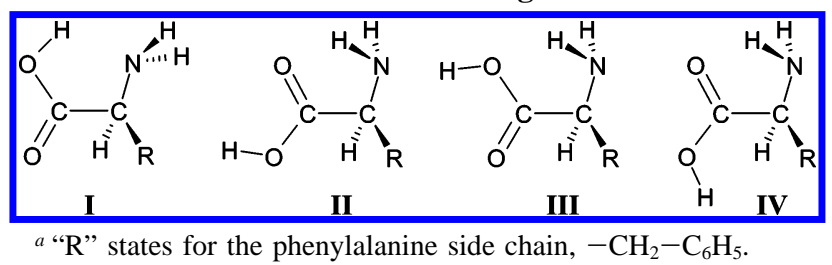

and $\mathrm{C}_{5}-\mathrm{N}_{7}\left(\mathrm{C}_{\alpha}-\mathrm{N}\right)$ internal axes. Table 1 presents the values of these dihedral angles in the twenty-five lowest-energy conformational minima together with relative energies and molecular dipole moments calculated at the B3LYP/6-311++G$(\mathrm{d}, \mathrm{p})$ level of theory. The conformer naming adopted in this work is also presented in Table 1 and deserves a detailed explanation.

There are four typical arrangements of the amino acid fragment designated by Roman numerals from I to IV (see Chart 2).

One of these numbers constitutes the first element of the name of a conformer and corresponds to the combination of two dihedral angles. The first dihedral angle, $\mathrm{O}=\mathrm{C}-\mathrm{O}-\mathrm{H}$, adopts the trans orientation (ca. $180^{\circ}$ ) in types I and IV, whereas types II and III correspond to the cis orientation (ca. $0^{\circ}$ ) with very small deviations from planarity (less than $2^{\circ}$; see Table 1 ). The second dihedral angle, $\mathrm{O}=\mathrm{C}-\mathrm{C}-\mathrm{N}$, adopts trans (or trans-like) orientation, with absolute values being above $109^{\circ}$, in types I and III. In types II and IV, the $\mathrm{O}=\mathrm{C}-\mathrm{C}-\mathrm{N}$ dihedral angle adopts cis (or cis-like) orientation, with absolute values being less than $60^{\circ}$.

The second element of the conformer's name is the letter "a", "b" or "c" which describes the relative position of the phenyl ring with respect to the amino acid fragment (Chart 3). 
CHART 3: Conformer Types Resulting from Different Orientations of the Side Chain (Exemplified for Type I Conformers) ${ }^{a}$

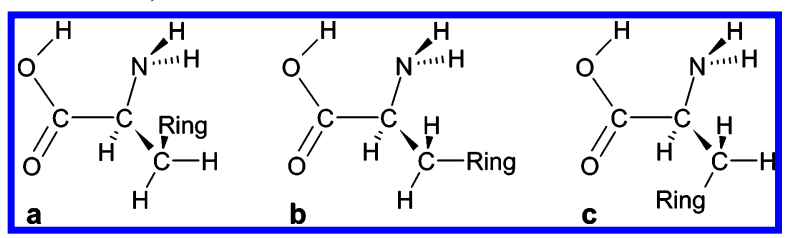

a "Ring" states for the phenyl ring, $-\mathrm{C}_{6} \mathrm{H}_{5}$.

This parameter is described by the value of the $\mathrm{C}_{1}-\mathrm{C}_{\alpha}-\mathrm{C}_{\beta}-\mathrm{C}_{\gamma}$ dihedral angle. This angle adopts essentially three possible orientations centered around average values of $-67.8^{\circ}$ (a), $169.8^{\circ}$ (b) and $66.6^{\circ}$ (c) with relatively small deviations (less than $10^{\circ}$ ). [Among the 25 most stable conformers, one form was found with a different arrangement around this axis, exhibiting a $C_{1}-C_{\alpha}-C_{\beta}-C \gamma$ dihedral angle of $96.1^{\circ}$. It was named Id (see Table 1).] A similar trend has been found for valine, where rotation around the $\mathrm{C}_{\alpha}-\mathrm{C}_{\beta}$ bond was studied systematically and showed the existence of a 3 -fold internal axis $^{24}$ with minima of $\mathrm{a}, \mathrm{b}$ and $\mathrm{c}$ type in conformers I, II and III.

The third element in the conformer's name is given by an Arabic numeral, "1", "2" or " 3 ". It corresponds to three different orientations of the lone pair of the nitrogen atom with respect to the $\mathrm{C}_{\alpha}-\mathrm{N}$ axis. As a general rule, in type I conformers the position of the lone pair is unique and corresponds to the cis orientation (absolute value around $29.6^{\circ}$ ) with respect to the $\mathrm{C}_{1}-\mathrm{C}_{\alpha}$ bond, because of the intramolecular hydrogen bond between the $\mathrm{NH}_{2}$ and $\mathrm{OH}$ groups [the exception occurs for the Ib type structure, where two orientations of the lone pair, differing by the sign ("cis" and "minus cis"), were found to correspond to minima]. In conformers of type II (or III) there are three possibilities of formation of intramolecular hydrogen bonds between the amino group and $\mathrm{C}=\mathrm{O}$ (or $\mathrm{C}-\mathrm{O}$ ) moiety. The intramolecular hydrogen bond can be bifurcated, corresponding to the lone pair in the trans position (around $173.3^{\circ}$ ). Alternatively, it can involve only one hydrogen atom of the amino group, when the lone pair adopts the "gauche" or "minus gauche" position (with average values of the $\mathrm{C}_{1}-\mathrm{C}_{\alpha}-\mathrm{N}-\mathrm{lp}$ dihedral angle being $78.9^{\circ}$ or $-62.4^{\circ}$, respectively). Three orientations of this dihedral angle are given by the index 1,2 or 3 . They are not related with the particular value of the dihedral angle $\mathrm{C}_{1}-\mathrm{C}_{\alpha}-\mathrm{N}-\mathrm{lp}$ but correspond to increasing relative energies.

Finally, there is one more dihedral angle, defining the position of the $\mathrm{C}_{\alpha}-\mathrm{C}_{\beta}$ axis with respect to the phenyl ring. For all conformers, this axis was found to be very close to the plane perpendicular to the plane of the phenyl ring (Table 1). All attempts to optimize a conformer where the $\mathrm{C}_{\alpha}-\mathrm{C}_{\beta}$ axis would be coplanar with the phenyl ring failed. Preferential perpendicular constraint of the $\mathrm{C}_{\alpha}-\mathrm{C}_{\beta}$ axis with respect to the phenyl ring has been confirmed experimentally by ENDOR spectroscopy of spin-labeled L-phenylalanine. ${ }^{42}$ The value of the $\mathrm{C}_{\alpha}-\mathrm{C}_{\beta}-\mathrm{C}_{\gamma}-$ (ring) dihedral angle for all conformers calculated in this study falls into a narrow and specific region of angles (deviation of $\pm 14^{\circ}$ from perpendicular). Interestingly, the same region of this angle is dominantly populated and characteristic of the phenylalanine residues in proteins. ${ }^{43-45}$ Thus, the dihedral angle $\mathrm{C}_{\alpha}-\mathrm{C}_{\beta}-\mathrm{C}_{\gamma}-$ (ring) was found to be uniform in all conformations and for this reason is not included in the conformers' names.

All conformers of type IV were found to have high relative energies. The most important low energy conformers belong to
TABLE 2: Geometry of the H-Bond (Distances in Å, Angles in deg) of the Most Stable Phe Conformers

\begin{tabular}{lllll}
\hline conformer & \multicolumn{1}{c}{$\mathrm{H}$-bond type } & \multicolumn{1}{c}{$\mathrm{X} \cdots \mathrm{H}$} & $\mathrm{X} \cdots \mathrm{Y}$ & $\angle \mathrm{Y}-\mathrm{H} \cdots \mathrm{X}$ \\
\hline $\mathrm{Ib}_{1}$ & (I) $\mathrm{O}_{3}-\mathrm{H}_{4} \cdots \mathrm{N}_{7}$ & 1.924 & 2.613 & 124.8 \\
$\mathrm{Ia}$ & & 1.869 & 2.600 & 126.0 \\
$\mathrm{Ib}$ & & 1.910 & 2.605 & 125.3 \\
$\mathrm{IIa}$ & $(\mathrm{II})$ & $2.775,2.771$ & 2.838 & $83.1,83.3$ \\
$\mathrm{IIb}_{1}$ & $\mathrm{~N}_{7}-\mathrm{H}_{8} \cdots \mathrm{O}_{2}$, &,- 2.432 & 2.772 &,- 98.6 \\
$\mathrm{IIb}_{2}$ & $\mathrm{~N}_{7}-\mathrm{H}_{9} \cdots \mathrm{O}_{2}$ & $2.506,3.126$ & 2.848 & $99.0,64.9$ \\
$\mathrm{IIc}_{1}$ & & $2.725,3.314$ & 2.996 & $95.3,63.2$ \\
$\mathrm{IIb}_{3}$ & &,- 2.326 & 2.723 &,- 101.9 \\
$\mathrm{IIc}_{2}$ & &,- 2.595 & 2.872 &,- 95.2 \\
$\mathrm{IIIb}_{1}$ & $(\mathrm{III})$ & $2.364,-$ & 2.708 & $98.6,-$ \\
$\mathrm{IIIa}$ & $\mathrm{N}_{7}-\mathrm{H}_{8} \cdots \mathrm{O}_{3}$, & $2.598,2.744$ & 2.736 & $86.8,78.9$ \\
$\mathrm{IIIb}_{2}$ & $\mathrm{~N}_{7}-\mathrm{H}_{9} \cdots \mathrm{O}_{3}$ &,- 2.436 & 2.718 &,- 94.9 \\
$\mathrm{IIIc}$ & &,- 2.699 & 2.975 &,- 95.6 \\
$\mathrm{IIIb}_{3}$ & &,- 2.485 & 2.833 &,- 99.4
\end{tabular}

types I, II and III (Table 1). Relevant calculated geometrical parameters of the H-bonds found in these conformers are shown in Table 2. The fourteen most-stable conformers of Phe are presented in Figure 1.

The two most stable conformers are of type $\mathrm{I}\left(\mathrm{Ib}_{1}\right.$ and Ia) and differ solely by the arrangement of the amino acid group with respect to the phenyl ring. In structures of type II and III the intramolecular $\mathrm{H}$-bond is formed between the amino proton(s) and the carbonyl and hydroxyl oxygen atom, respectively. The H-bond is nearly symmetrically bifurcated for conformer $\mathrm{IIa}_{1}$. The local asymmetry of the H-bonding system is growing in the order $\mathrm{IIb}_{2}<\mathrm{IIc}_{1}<\mathrm{IIb}_{1}, \mathrm{IIb}_{3}, \mathrm{IIc}_{2}$, practically turning into a single bond for the latter three forms (see Table 2 ). With the increase in the asymmetry, the stability of the structure decreases with the exception of structure $\mathrm{IIb}_{1}$. Analogous behavior was predicted for type III structures. However, in this case, only $\mathrm{III}_{1}$ displays a bifurcated $\mathrm{H}$-bond.

3.2. Energies and Abundances of Phe Conformers and Conformational Interconversion Barriers. The physicochemical bases of amino acid preferences for $\alpha$-helical, $\beta$-strand and other main-chain conformational states in proteins are controversial. The hydrophobic effect, side-chain conformational entropy, steric factors, and main-chain electrostatic interactions have all been advanced as the dominant physical factors that determine these preferences. ${ }^{46}$ It has been shown for amino acids $^{47}$ that restriction of side chain motion is enthalpically favorable. This is because the hindered rotation will be on average closer to the bottom of the potential energy well. On the other hand, the restricting of internal rotations is unfavorable in terms of Gibbs energy and entropy, as a smaller range of dihedral angles can be sampled. ${ }^{47}$

Table 3 presents the calculated relative zero-point-corrected energies, Gibbs free energies and abundances (at the sublimation temperature used in this study and $298.15 \mathrm{~K}$ ) of the most stable conformers of phenylalanine.

It is clear from Table 3 that the zero-point-corrected relative energies do not follow the order of Gibbs free energies at 423.15 $\mathrm{K}$. Thus, it is then evident that entropy effects are important for the thermochemistry of Phe and should be taken into account when determining the relative abundances of the various conformers of this compound in experiment. However, contrary to the alanine, ${ }^{23}$ the observed differences in the order of the zero-point-corrected energies and Gibbs free energies cannot be explained solely by the entropic cost associated with formation of H-bonds. Restriction of internal rotation in general is important in phenylalanine. For instance, conformers $\mathrm{IIb}_{1}$ and $\mathrm{IIb}_{2}$ have the same type of intramolecular hydrogen bond, but the latter is entropically favored in relation to the former (see 


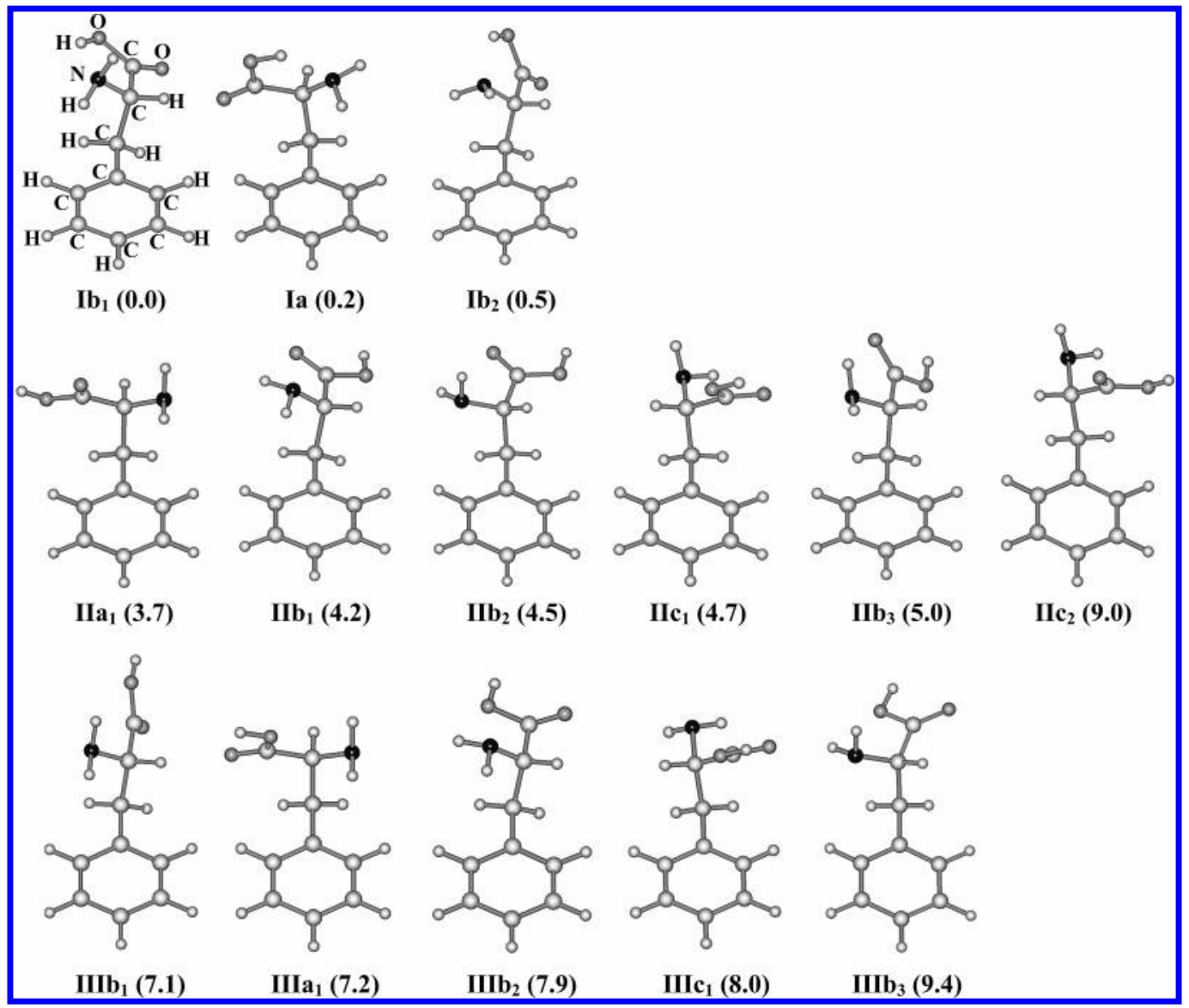

Figure 1. Optimized $[\mathrm{B} 3 \mathrm{LYP} / 6-311++\mathrm{G}(\mathrm{d}, \mathrm{p})]$ geometries of the most stable conformers of Phe. The values of the zero-point-corrected energy relative to the most-stable conformer (in $\mathrm{kJ} \mathrm{mol}^{-1}$ ) are given in the parentheses.

Table 3). Indeed, in conformer $\mathrm{Ilb}_{1}$, the $\mathrm{NH}_{2}$ group is hovering over the phenyl ring. Thus, internal rotation of the amino group can be considered as internally hindered in this conformer. On the other hand, in conformer $\mathrm{IIb}_{2}$, the amino group does not experience any steric constraint due to interactions with the ring. Conformer $\mathrm{IIb}_{1}$ is enthalpically favored at $0 \mathrm{~K}$, but the greater flexibility inherent of conformer $\mathrm{IIb}_{2}$ makes this form to be favored by entropy. At $423.15 \mathrm{~K}$, conformer $\mathrm{IIb}_{1}$ has a Gibbs free energy $2.7 \mathrm{~kJ} \mathrm{~mol}^{-1}$ higher than conformer $\mathrm{IIb}_{2}$, despite having an enthalpy $0.7 \mathrm{~kJ} \mathrm{~mol}^{-1}$ lower than this form. The entropic cost $\left(-T \Delta S_{\mathrm{Ia}-\mathrm{Ib}}=-3.4 \mathrm{~kJ} \mathrm{~mol}^{-1}\right.$ at $\left.423.15 \mathrm{~K}\right)$ resulting from the larger steric hindrance in conformer $\mathrm{IIb}_{1}$ when compared with $\mathrm{IIb}_{2}$ leads to a positive value of $\Delta G\left(\mathrm{IIb}_{1}-\mathrm{IIb}_{2}\right)$.

A similar, however not so prominent, effect is observed for conformers of type I. Conformer Ia is enthalpically favored at $423 \mathrm{~K}$ by $0.2 \mathrm{~kJ} \mathrm{~mol}^{-1}$ relative to conformer $\mathrm{Ib}_{1}$. However, the higher internal flexibility of this latter form leads to its stabilization and makes it the most stable conformer. These conclusions are in consonance with the previously proposed relevance of the daisy-chain sequence of interactions between aromatic $\pi$-electrons, the amino group and the carboxylic $\mathrm{OH}$ group in aromatic amino acids. ${ }^{9}$ In the case of conformer Ia, where the amino group "hovers" above the ring plane, this daisychain is stronger than for the $\mathrm{Ib}_{1}$ form, where the carboxylic group is too far to interact with the $\pi$-electrons. Therefore, the interaction between the carboxylic moiety and the ring is responsible for the entropic destabilization of form Ia relative to $\mathrm{Ib}_{1}$. The effect is, naturally, more prominent at higher temperatures (see Table 3).

The importance of the interactions involving the amino or carboxylic group and the phenyl ring as contributors to reduce the entropy of a given conformer can also be noticed by comparing the other two groups of conformers (II and III). In both cases, a-type conformers (i.e., $\mathrm{IIa}_{1}$ and $\mathrm{IIIa}_{1}$ ) are destabilized by entropy relative to either b- or c-type conformers, because in the a-type forms the steric interactions involve always both amino/phenyl and carboxyl/phenyl interactions, whereas in b-type and c-type conformers only amino/phenyl or carboxyl/ phenyl interactions, respectively, may be present. Two additional conclusions can be extracted by comparing the relative stabilization of b- and c-type conformers relative to a-forms in groups II and III (see Table 3 and also Figure 1): (i) in cases where the amino hydrogen atom(s) point to the phenyl ring, the carboxyl/phenyl interaction is entropically less destabilizing (i.e., it gives less rigidity to the molecule and, thus, is weaker) than the amino/phenyl interaction (note, for instance, the entropy stabilization of IIc $c_{1}$ and $\mathrm{IIc}_{2}$ when compared with those of IIb and $\mathrm{IIb}_{3}$ relative to $\mathrm{IIa}_{1}$ ); (ii) on the other hand, when the lone electron pair of the nitrogen points toward the phenyl ring and the amino hydrogens are far away from it, the entropic stabilization is maximized, as noticed by the large $T \Delta S$ values calculated for $\mathrm{IIb}_{2}$ and $\mathrm{IIIb}_{3}$ (Table 3; see also Figure 1), which indicates that in this case the amino/phenyl interaction imposes a comparatively much lower important rigidity on the molecule.

The effects of different hydrogen bond strengths on the entropy of the different conformers can be analyzed better by comparing conformers where the steric, daisy-chain, effects can be expected to be almost identical. Hence, both conformer $\mathrm{IIa}_{1}$ and IIIa $_{1}$ shall be compared with Ia, whereas forms $\mathrm{IIb}_{1}$ and $\mathrm{IIIb}_{1}$ shall be compared with $\mathrm{Ib}_{1}$. Note that in this case, IIb and $\mathrm{IIIb}_{3}$ are not directly comparable with $\mathrm{Ib}_{1}$, because they have different daisy-chain interactions, as mentioned above. In addition, comparison for c-type conformers is also not illustrative, because in this case the $\mathrm{OH} \cdots \mathrm{N}$ bond is much weaker than 
TABLE 3: Relative Zero-Point Energies $\left(\Delta E_{\text {corr }} / \mathbf{k J ~ m o l}^{-1}\right)$, Enthalpies $\left(\Delta H_{423} / \mathrm{kJ} \mathrm{mol}^{-1}\right)$, Entropic Contributions $\left(T \Delta S_{423} / \mathrm{kJ} \mathrm{mol}^{-1}\right)$, Gibbs Free Energies $\left(\Delta G / \mathrm{kJ} \mathrm{mol}^{-1}\right)$ and Abundances of the Most Stable Phe Conformers Calculated on the Basis of $\Delta \boldsymbol{G}$ values $(\%)$

\begin{tabular}{|c|c|c|c|c|c|c|c|c|}
\hline conformer $^{a}$ & $\Delta E_{\text {corr }}^{b}$ & $\Delta H_{423^{c}}{ }^{c}$ & $T \Delta S_{423^{c}}$ & $\Delta G_{423}{ }^{c}$ & $\Delta G_{298}{ }^{d}$ & $\%_{423^{e}}$ & $\%_{423 \mathrm{~A}^{f}}$ & $\%_{298^{g}}$ \\
\hline $\mathrm{Ib}_{1}$ & 0.0 & 0.0 & 0.0 & 0.0 & 0.0 & 14.3 & 14.3 & 25.1 \\
\hline Ia & 0.2 & -0.2 & 2.2 & 2.0 & 1.4 & 8.1 & 8.1 & 14.4 \\
\hline $\mathrm{IIa}_{1}$ & 3.7 & 4.7 & -2.2 & 2.6 & 3.2 & 6.9 & 6.9 & 7.0 \\
\hline $\mathrm{IIb}_{1}$ & 4.2 & 5.4 & -3.2 & 2.2 & 3.1 & 7.7 & 7.7 & 7.3 \\
\hline $\mathrm{IIb}_{2}$ & 4.5 & 6.1 & -6.6 & -0.5 & 1.4 & 16.6 & 28.9 & 14.5 \\
\hline $\mathrm{IIc}_{1}$ & 4.7 & 6.0 & -5.9 & 0.1 & 1.8 & 13.8 & 13.8 & 12.1 \\
\hline $\mathrm{IIb}_{3}$ & 5.0 & 6.2 & -3.2 & 3.0 & 3.9 & 6.1 & $0.0^{h}$ & 5.3 \\
\hline $\mathrm{IIIb}_{1}$ & 7.1 & 8.2 & -3.8 & 4.4 & 5.5 & 4.1 & $4.1^{h}$ & 2.7 \\
\hline $\mathrm{IIIa}_{1}$ & 7.2 & 8.0 & -1.7 & 6.3 & 6.7 & 2.4 & $2.4^{h}$ & 1.7 \\
\hline $\mathrm{IIIb}_{2}$ & 7.9 & 9.3 & -4.5 & 4.8 & 6.0 & 3.7 & $3.7^{h}$ & 2.2 \\
\hline $\mathrm{IIIc}_{1}$ & 8.0 & 9.3 & -4.1 & 5.2 & 6.4 & 3.2 & $3.2^{h}$ & 1.9 \\
\hline $\mathrm{IIc}_{2}$ & 9.0 & 10.3 & -4.7 & 5.6 & 6.9 & 2.9 & $2.9^{h}$ & 1.5 \\
\hline $\mathrm{IIIb}_{3}$ & 9.4 & 11.1 & -8.1 & 3.0 & 5.3 & 6.2 & $0.0^{h}$ & 3.0 \\
\hline $\mathrm{IIa}_{2}$ & 11.2 & 12.3 & -1.8 & 10.5 & 11.0 & 0.7 & $0.7^{h}$ & 0.3 \\
\hline Ic & 12.5 & 12.7 & -1.1 & 11.6 & 11.9 & 0.5 & $0.5^{h}$ & 0.2 \\
\hline $\mathrm{IIIc}_{2}$ & 13.1 & 14.6 & -4.5 & 10.1 & 11.4 & 0.8 & $0.8^{h}$ & 0.3 \\
\hline Id & 13.1 & 13.1 & -1.4 & 11.7 & 12.1 & 0.5 & $0.5^{h}$ & 0.2 \\
\hline $\mathrm{IIIa}_{2}$ & 13.5 & 14.4 & -1.6 & 12.8 & 13.2 & 0.4 & $0.4^{h}$ & 0.1 \\
\hline $\mathrm{IIIc}_{3}$ & 13.7 & 14.8 & -2.8 & 12.0 & 12.8 & 0.5 & $0.5^{h}$ & 0.1 \\
\hline $\mathrm{IIc}_{3}$ & 15.7 & 17.2 & -5.5 & 11.6 & 13.2 & 0.5 & $0.5^{h}$ & 0.1 \\
\hline $\mathrm{IVc}_{1}$ & 19.7 & 21.4 & -5.2 & 16.2 & 17.6 & 0.1 & $0.1^{h}$ & 0.0 \\
\hline
\end{tabular}

${ }^{a} \mathrm{~B} 3 \mathrm{LYP} / 6-311++\mathrm{G}(\mathrm{d}, \mathrm{p})$; all structures have $C_{1}$ symmetry. ${ }^{b} E_{\text {corr }}=-554.773343$ hartree for conformer $\mathrm{Ib}_{1} \cdot{ }^{c} H, S$ and $G$ values calculated at $423.15 \mathrm{~K}\left(G_{423}=-554.834106\right.$ and $H_{423}=-554.751204$ hartree for conformer $\left.\mathrm{Ib}_{1}\right){ }^{d} G$ values calculated at $298.15 \mathrm{~K}\left(G_{298}=\right.$ -554.811392 hartree for conformer $\left.\mathrm{Ib}_{1}\right){ }^{e}$ Abundance of conformers at $423.15 \mathrm{~K} .{ }^{f}$ Abundance of conformers at $423.15 \mathrm{~K}$ including expected interconversion of conformers, $\mathrm{IIb}_{3} \rightarrow \mathrm{IIb}_{2}$ and $\mathrm{IIIb}_{3} \rightarrow \mathrm{IIb}_{2} .{ }^{g}$ Abundance of conformers at $298.15 \mathrm{~K} .{ }^{h}$ Not identified experimentally.

for b- and a-type conformers as revealed by its longer $\mathrm{H} \cdots \mathrm{N}$ bond length and smaller $\angle \mathrm{O}-\mathrm{H} \cdots \mathrm{N}$ angle, calculated as 1.959 $\AA$ and $122.9^{\circ}$, respectively. Conformers of types II and III have hydrogen bonds of a different kind that are, in both cases, weaker than in conformers of type I. $\Delta E_{\text {corr }}$ values for conformers of types II and III relative to directly comparable conformers of type I show that the intramolecular H-bonds in these two types of conformers are weaker than in forms I by 3.5-4.0 and $6.5-7.5 \mathrm{~kJ} \mathrm{~mol}^{-1}$, respectively (Table 3). [Conformer $\mathrm{IIc}_{2}$ is an exception, having a much higher relative energy than expected (approximately double; $9 \mathrm{~kJ} \mathrm{~mol}^{-1}$ ). This is due to the presence of $\mathrm{H} \cdots \mathrm{H}$ repulsions between the $\mathrm{NH}_{2}$ and $\mathrm{CH}_{2}$ hydrogen atoms, which are face-to-face and close to each other in this form.] Accordingly, both conformer types, i.e., II and III, are favored by entropy relative to type I where the relative $T \Delta S_{423}$ values are in the range $1.5-4.5 \mathrm{~kJ} \mathrm{~mol}^{-1}$ (see Table 3).

Because all conformers have the same degeneracy, their abundance in the equilibrium gaseous phase follows the order of Gibbs free energies. There are eight structures $\left(\mathrm{IIb}_{2}, \mathrm{Ib}_{1}, \mathrm{IIc}_{1}\right.$, $\mathrm{Ia}, \mathrm{IIb}_{1}, \mathrm{IIa}_{1}, \mathrm{IIb}_{3}, \mathrm{IIIb}_{3}$ ) with abundances exceeding $5 \%$ at $423.15 \mathrm{~K}$, whereas the remaining conformers have abundances below 4\%. On the other hand, as already mentioned, the abundance of conformers in a low-temperature matrix may change because of conformer interconversion either during deposition of the matrix or in the matrix itself, depending on the energy barriers separating the conformers. In a supersonic jet, a value of ca. $5 \mathrm{~kJ} \mathrm{~mol}^{-1}$ was proposed for the maximum barrier, allowing relaxation to a lower-energy conformer after expansion from room temperature. ${ }^{48}$ In matrixes, conformational cooling has been demonstrated to occur in glycine, sarcosine and other related $\alpha$-substituted carbonyl compounds possessing barriers to intramolecular rotation of only a few $\mathrm{kJ} \mathrm{mol}^{-1} \cdot 15,19,49,50$ Therefore, the conformational interconversion barriers between the relevant conformers of phenylalanine (in particular those conformers whose geometries differ essentially by the value of one torsion angle) were calculated to evaluate the possibility of this phenomenon to take place also in this molecule. The computed interconversion energy barriers are presented in Table 4.

As expected, the conformational barriers involving cis-trans rotation of the carboxylic group (42.4 and $49.6 \mathrm{~kJ} \mathrm{~mol}^{-1}$ for conversion of $\mathrm{IIIb}_{1}$ into $\mathrm{Ib}_{1}$ ) are considerably higher than all the others. Thus, the possibility of conversion between forms of types II and III into a conformer belonging to group I both

TABLE 4: Theoretical Values of Conformational Interconversion Barriers for Selected Conformers of Phe (kJ mol $\left.{ }^{-1}\right)^{a, b}$

\begin{tabular}{|c|c|c|c|c|c|c|c|c|c|c|c|c|c|c|}
\hline & $\mathrm{Ib}_{1}$ & Ia & $\mathrm{Ib}_{2}$ & $\mathrm{IIa}_{1}$ & $\mathrm{IIb}_{1}$ & $\mathrm{IIb}_{2}$ & $\mathrm{IIc}_{1}$ & $\mathrm{IIb}_{3}$ & $\mathrm{IIIb}_{1}$ & $\mathrm{IIIa}_{1}$ & $\mathrm{IIIb}_{2}$ & IIIc $_{1}$ & $\mathrm{IIc}_{2}$ & $\mathrm{IIIb}_{3}$ \\
\hline $\mathrm{Ib}_{1}$ & & & 0.5 & & & & & & $\begin{array}{l}49.5 \\
56.7\end{array}$ & & & & & \\
\hline $\begin{array}{l}\mathrm{Ia} \\
\mathrm{Ib}_{2}\end{array}$ & 0.03 & 16.3 & 16.5 & & & & & & & & & & & \\
\hline $\mathrm{IIa}_{1}$ & & & & & & 19.6 & 18.6 & & & $\begin{array}{l}13.0 \\
16.3\end{array}$ & & & & \\
\hline $\mathrm{IIb}_{1}$ & & & & & & 5.5 & & 12.2 & & & $\begin{array}{l}11.8 \\
19.2\end{array}$ & & 16.6 & \\
\hline $\mathrm{IIb}_{2}$ & & & & 18.9 & 5.20 & & 10.0 & 1.5 & & & & & & $\begin{array}{r}7.1 \\
11.0\end{array}$ \\
\hline $\begin{array}{l}\mathrm{IIc}_{1} \\
\mathrm{IIb}_{3}\end{array}$ & & & & 17.6 & 11.4 & $\begin{array}{l}9.7 \\
0.9\end{array}$ & & & $\begin{array}{r}8.9 \\
10.6\end{array}$ & & & 11.7 & 10.0 & \\
\hline $\mathrm{IIIb}_{1}$ & $\begin{array}{l}42.0 \\
49.6\end{array}$ & & & & & & & $\begin{array}{l}6.8 \\
8.5\end{array}$ & & & 10.1 & & & 6.7 \\
\hline $\mathrm{IIIa}_{1}$ & & & & $\begin{array}{r}9.6 \\
12.9\end{array}$ & & & & & & & & 20.2 & & \\
\hline $\mathrm{IIIb}_{2}$ & & & & & $\begin{array}{r}8.1 \\
15.4\end{array}$ & & & & 9.3 & & & & & 9.1 \\
\hline $\begin{array}{l}\mathrm{IIIc}_{1} \\
\mathrm{IIc}_{2}\end{array}$ & & & & & 11.8 & & $\begin{array}{l}8.4 \\
5.7\end{array}$ & & & 19.4 & & & & \\
\hline $\mathrm{IIIb}_{3}$ & & & & & & $\begin{array}{l}2.2 \\
6.1\end{array}$ & & & 4.3 & & 7.5 & & & \\
\hline
\end{tabular}


during deposition of the matrixes and in the matrixes can be safely excluded. The barriers for internal rotation around the $\mathrm{C}_{\alpha}-\mathrm{C}_{\beta}$ bond (changes between conformers $\mathrm{a}, \mathrm{b}, \mathrm{c}$ ) are in the $10-20 \mathrm{~kJ} \mathrm{~mol}^{-1}$ range; therefore they cannot be overcome either. On the other hand, lower values were obtained for the barriers connected with rotation around $\mathrm{C}_{\alpha}-\mathrm{C}_{1}$ (interconversion between conformers of types II and III) and $\mathrm{C}_{\alpha}-\mathrm{N}$ bonds (interconversion between conformers of types 1,2 and 3), which are usually in the $7-13$ and $5-12 \mathrm{~kJ} \mathrm{~mol}^{-1}$ ranges, respectively. Notably, only two barriers were found to be very low: 0.9 and $2.2 \mathrm{~kJ} \mathrm{~mol}^{-1}$, for conversion of $\mathrm{IIb}_{3}$ and $\mathrm{IIIb}_{3}$, respectively, into $\mathrm{IIb}_{2}$. These barriers are low enough to be surpassed during matrix deposition, resulting in relaxation of both conformers $\left(\mathrm{IIb}_{3}\right.$ and $\mathrm{IIIb}_{3}$ ) into $\mathrm{IIb}_{2}$.

Another important remark that should be done here is connected with the $\mathrm{Ib}_{2}$ structure. Although this structure is formally a minimum on the potential energy surface (justifying its consideration in the discussion of geometries), it cannot in fact be treated as an independent state even at $0 \mathrm{~K}$. Indeed, accordingly to the calculations, the energy barrier for conversion of this structure into the most stable conformer $\left(\mathrm{Ib}_{1}\right), 0.03 \mathrm{~kJ}$ $\mathrm{mol}^{-1}$, stays below the zero-point vibrational level of the coordinate $\left(\tau_{\mathrm{NH}_{2}}\right)$ associated with this transformation (see Table 4). In any case, even with such a low barrier to conversion, existence of a double minimum $\left(\mathrm{Ib}_{1}\right.$ and $\left.\mathrm{Ib}_{2}\right)$ would imply degeneracy in the vibrational levels. However, because harmonic frequency calculations cannot handle this kind of systems at all, it is not possible to predict the effects of the energy levels degeneracy on the absorption cross sections. In the absence of a full treatment, any quantitative consideration of such effects would be arbitrary. A possibility would be to add the population from $\mathrm{Ib}_{2}$ to $\mathrm{Ib}_{1}$ in the same way as $\mathrm{IIb}_{3}$ contributed to $\mathrm{IIb}_{2}$. To test this hypothesis, we compared the experimental spectra with two different simulated abundance-weighted spectra. In one of them, the abundance of conformer $\mathrm{Ib}_{2}$ was added to the abundance of the conformer $\mathrm{Ib}_{1}$ and, in the other, it was not. The aggrement is better in the latter case, suggesting that existence of the "extra" minimum does not lead to strong changes in the absorption cross sections. An alternative explanation is conformer $\mathrm{Ib}_{2}$ being just an artifact of the computations.

3.3. Vibrational Spectrum of Matrix-Isolated Phe. The FT-IR spectrum of matrix-isolated Phe is given in Figures 2-4 and its detailed assignment, based on calculated PED of normal modes, is provided in the Supporting Information (Tables $1 \mathrm{~S}$ and $2 \mathrm{~S}$ ).

Due to the conformational flexibility of Phe, broad and superimposed bands are observed in the experimental spectrum. Nevertheless, the spectrum could be nicely fitted by theoretically predicted spectrum obtained by summing the population weighted calculated spectra of the six lowest-energy conformers, namely $\mathrm{Ia}, \mathrm{Ib}, \mathrm{IIa}_{1}, \mathrm{IIb}_{1}, \mathrm{IIb}_{2}$ and $\mathrm{IIc}_{1}$. The comparison of the experimental and calculated spectra could then be used to make tentative assignment of bands to individual conformers (Tables $1 \mathrm{~S}$ and 2S). It is important to stress that the presented assignment has to be treated as tentative due to similarities in the spectra of conformers belonging to the same type from the point of view of orientation of the amino acid group in respect to the ring, i.e., types I or II. Nevertheless, the existence of these two types of conformations as well as the estimation of their respective total abundances could be done on the basis of the obtained spectra, as indicated below. On the other hand, putative features ascribable to other low-energy conformers could not be identified owing to low abundance (for $\mathrm{IIc}_{2}, \mathrm{IIIb}_{1}, \mathrm{IIIa}_{1}, \mathrm{IIIb}_{2}$ and $\mathrm{IIIc}_{1}$, see also Table 3 ) or, as already mentioned, due to

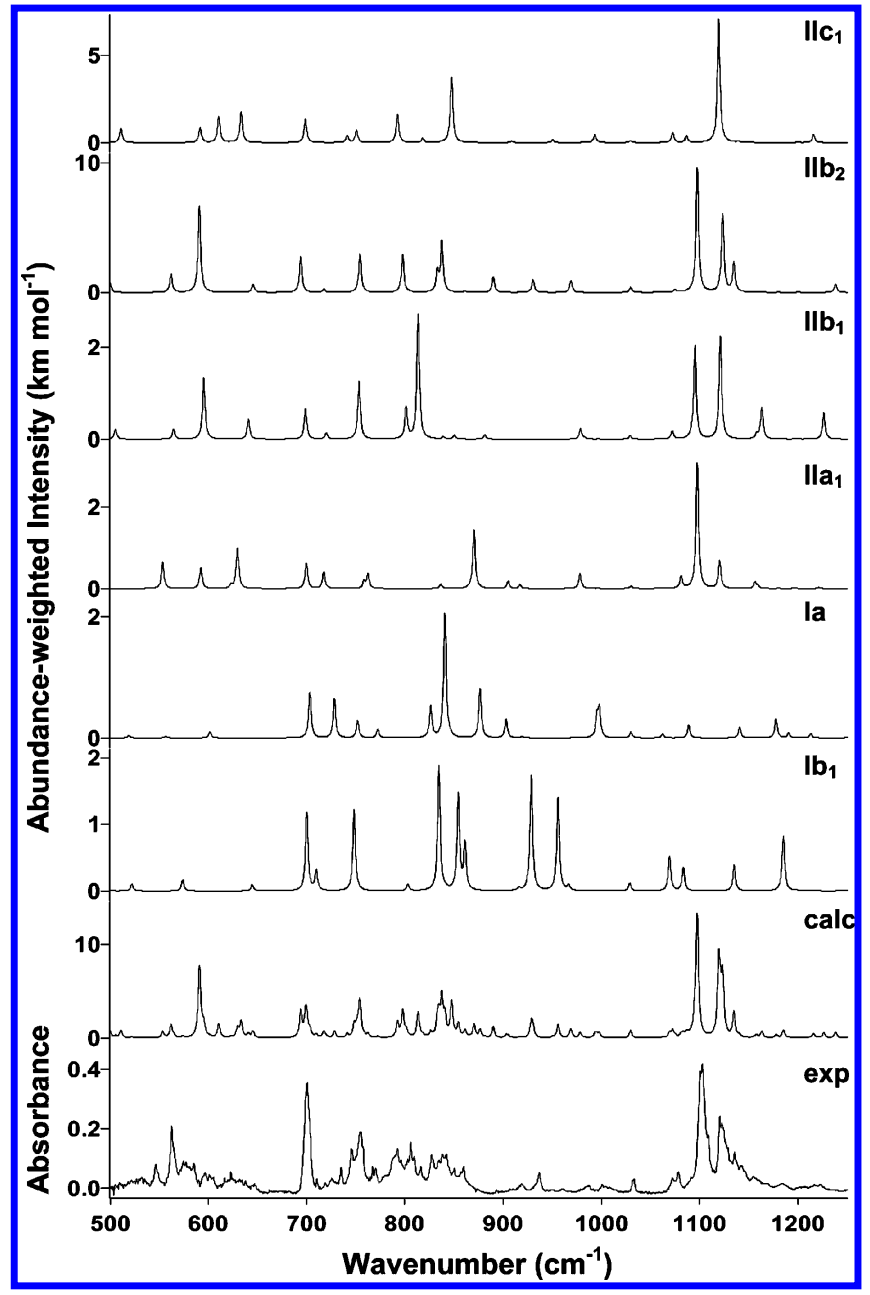

Figure 2. Comparison of the FT-IR spectrum of matrix-isolated Phe (exp) with the computed spectra $[\mathrm{B} 3 \mathrm{LYP} / 6-311++\mathrm{G}(\mathrm{d}, \mathrm{p})]$ of the six identified conformers $\left(\mathrm{Ib}_{1}-\mathrm{IIc}_{1}\right)$ and their sum spectrum (calc) in the $500-1250 \mathrm{~cm}^{-1}$ range. Theoretical intensities were scaled by the computed abundance of the given conformer (Table 3, \% ${ }_{423 \mathrm{~A}}$ ). Calculated wavenumbers were scaled by the factor of 0.98 .

conformational cooling during deposition of the matrix $\left(\mathrm{IIb}_{3} \rightarrow \mathrm{IIb}_{2}\right.$ and $\left.\mathrm{IIIb}_{3} \rightarrow \mathrm{IIb}_{2}\right)$. The significant increase of population of conformer $\mathrm{IIb}_{2}$ resulting from relaxation of higher energy forms predicted by calculations was in a good correspondence with the experimental data.

It is worthwhile to make here a brief comment regarding the nonidentification in the experimental spectra of bands due to type III conformers. From Table 3 it can be seen that the sum of populations due to all forms III (excluding $\mathrm{IIIb}_{3}$ ) is estimated as equal to ca. $15 \%$ of total population, at the relevant temperature. Fifteen percent is not so negligible with respect to $61.4 \%$ (overall population of forms of type II) and certainly not relative to $23.4 \%$ (all forms of type I). However, in the most relevant spectral regions (e.g., $\mathrm{OH}, \mathrm{C}=\mathrm{O}$ and $\mathrm{C}-\mathrm{O}$ stretching and $\mathrm{COH}$ bending regions), conformers of type III were predicted to absorb nearly at the same frequency as type II conformers. Their contribution to the relevant spectral features is then largely minoritary (specially when peak intensities are taken into consideration) and taking also into account that the total intensity of a given vibration due these type of conformers must also distribute itself by different (though similar) frequencies, it is easy to understand why no bands could be ascribed to type III conformers. On the other hand, type I conformers have substantially different vibrational signatures in the most characteristic spectral regions when compared to both type II 


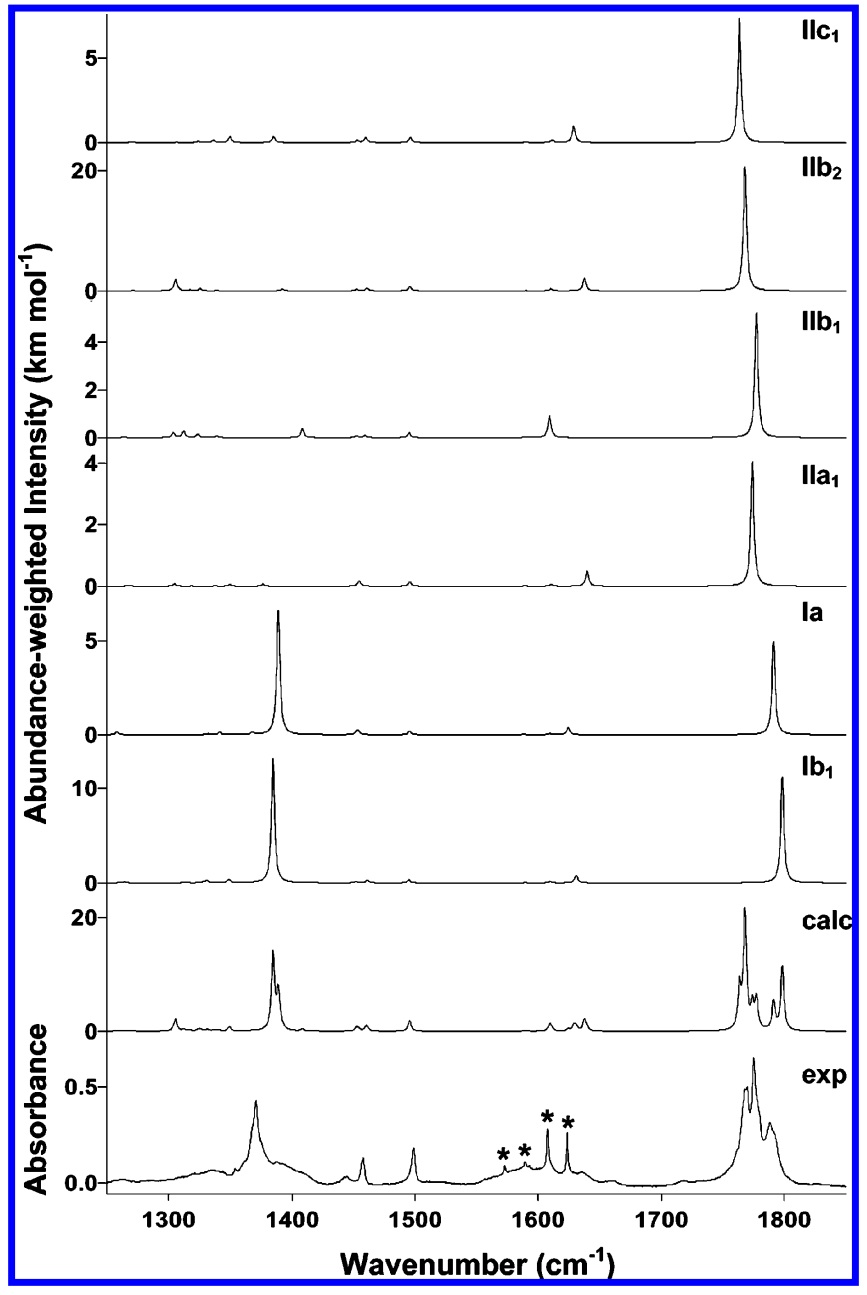

Figure 3. Comparison of the FT-IR spectrum of matrix-isolated Phe (exp) with the computed spectra [B3LYP/6-311++G(d,p)] of the six identified conformers $\left(\mathrm{Ib}_{1}-\mathrm{IIc}_{1}\right)$ and their sum spectrum (calc) in the $1250-1850 \mathrm{~cm}^{-1}$ range. Asterisks denote bands related to monomeric water vibrations. ${ }^{51}$ Theoretical intensities were scaled by the computed abundance of the given conformer (Table 3, \% ${ }_{423 \mathrm{~A}}$ ). Calculated wavenumbers were scaled by the factor of 0.98 .

and III forms, which could be easily identified in the experimental spectrum.

Note also that the accuracy of the calculations in predicting vibrational shifts with conformation is an important element to take into account in the interpretation of the experimental data made in this work. Accumulated experience clearly demonstrates that for the type of molecule under analysis, the level of theory used to compute the vibrational spectra is accurate enough to be applied successfully. ${ }^{19,20,52-54}$

Taking into consideration the great complexity of the system under study, the overall agreement of the experimental and theoretical sum-spectra can be considered good. The correspondence is comparatively worse in the higher wavenumber range $\left(3100-3600 \mathrm{~cm}^{-1}\right)$, for bands associated with the $\mathrm{O}-\mathrm{H}$ and $\mathrm{N}-\mathrm{H}$ stretching vibrations, owing to the higher anharmonicity of these vibrations.

To further assist in band assignment and identification of the conformers present in the matrix, annealing experiments were undertaken. Annealing of the matrix to higher temperatures (until $33 \mathrm{~K}$ ) resulted in the nonequivalent decrease of signal intensity of nearly all bands assigned to monomeric Phe and increase of low-intensity absorbances ascribable to aggregates of the compound. The different pattern of variation of band intensities observed for the features due to monomeric species can be

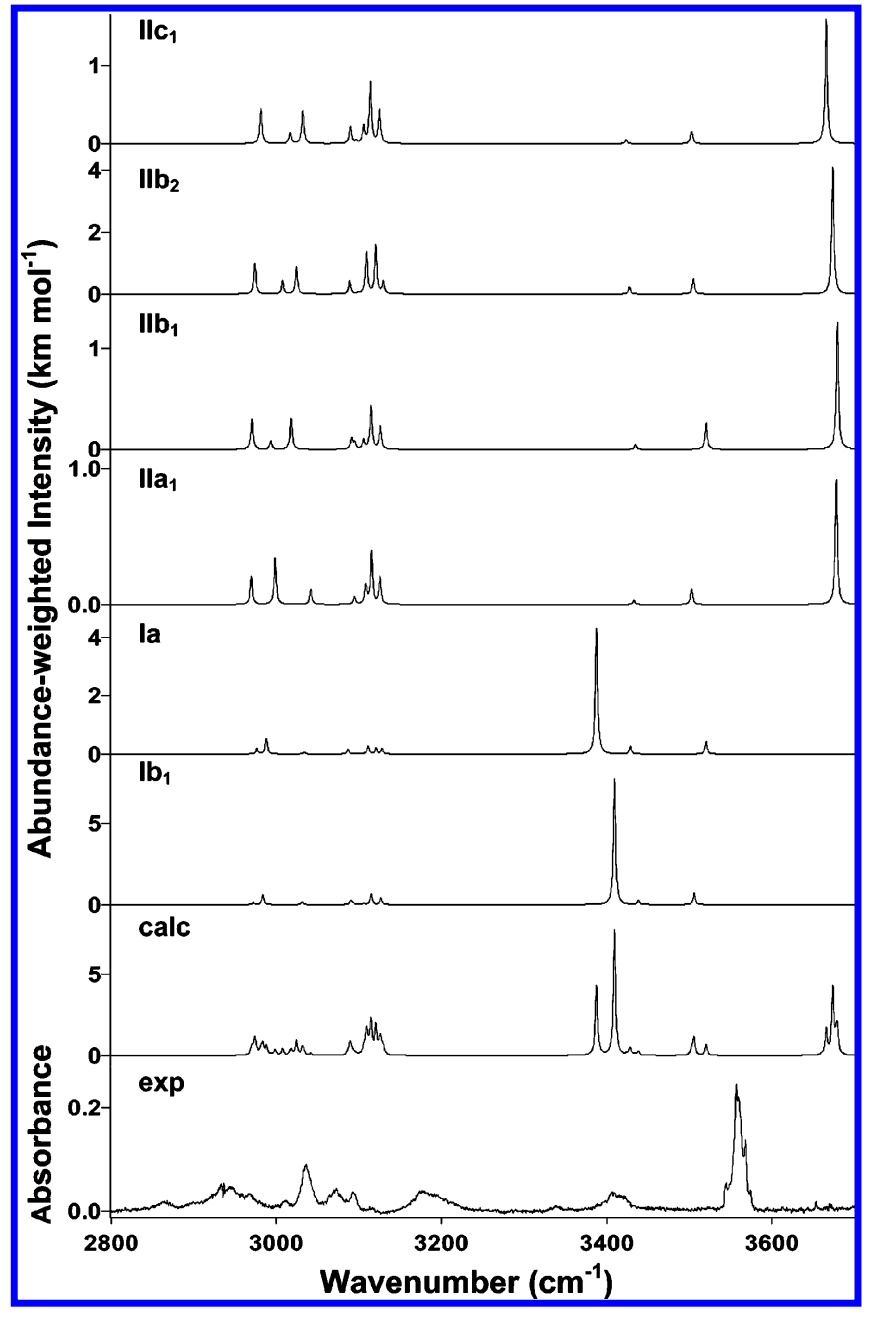

Figure 4. Comparison of the FT-IR spectrum of matrix-isolated Phe (exp) with the computed spectra [B3LYP/6-311++G(d,p)] of the six identified conformers $\left(\mathrm{Ib}_{1}-\mathrm{IIc}_{1}\right)$ and their sum spectrum (calc) in the $2800-3700 \mathrm{~cm}^{-1}$ range. Theoretical intensities were scaled by the computed abundance of the given conformer (Table 3, \% ${ }_{423 \mathrm{~A}}$ ). Calculated wavenumbers were scaled by the factor of 0.98 .

rationalized in terms of conformer-dependent aggregation of Phe in the matrix. This phenomenon has already been previously observed for $N, N$-dimethylglycine. ${ }^{20}$

$\mathrm{C}-\mathrm{O}$ and $\mathrm{C}-\mathrm{N}$ Stretching and $\mathrm{C}-\mathrm{O}-\mathrm{H}$ Bending Region. Frequencies of the $\mathrm{C}-\mathrm{O}$ stretching vibration are significantly different for the carboxylic group in the trans (I) and cis (II, III) arrangements; higher wavenumbers and lower intensity are expected for this absorption for the carboxylic group in cis conformation. Therefore, the presence of multiple bands in the $1060-1160 \mathrm{~cm}^{-1}$ range (see Figure 2) proves that several conformers of type II are present in the matrix (from the experimental data, forms of type III cannot be ruled out but, as mentioned above, they must be in a very minor amount and, in practical terms, could not be identified). The qualitative agreement of the theoretical and experimental spectra allows for, at least tentative, assignment of the bands to different conformers of type II (see Table 2S).

The set of several superimposed bands with seven main intensity maxima at 1101, 1103, 1109 (shoulder), 1120, 1122, 1125 (shoulder) and 1128 (shoulder) $\mathrm{cm}^{-1}$ is observed in this range. In the same spectral region, computations predict six strong absorptions related to vibrations of the four lowest-energy conformers of type II $\left(\mathrm{IIa}_{1}, \mathrm{IIb}_{1}, \mathrm{IIb}_{2}, \mathrm{IIc}_{1}\right)$. Annealing brings a slight increase of the intensity of the band at $1120 \mathrm{~cm}^{-1}$ at 24 


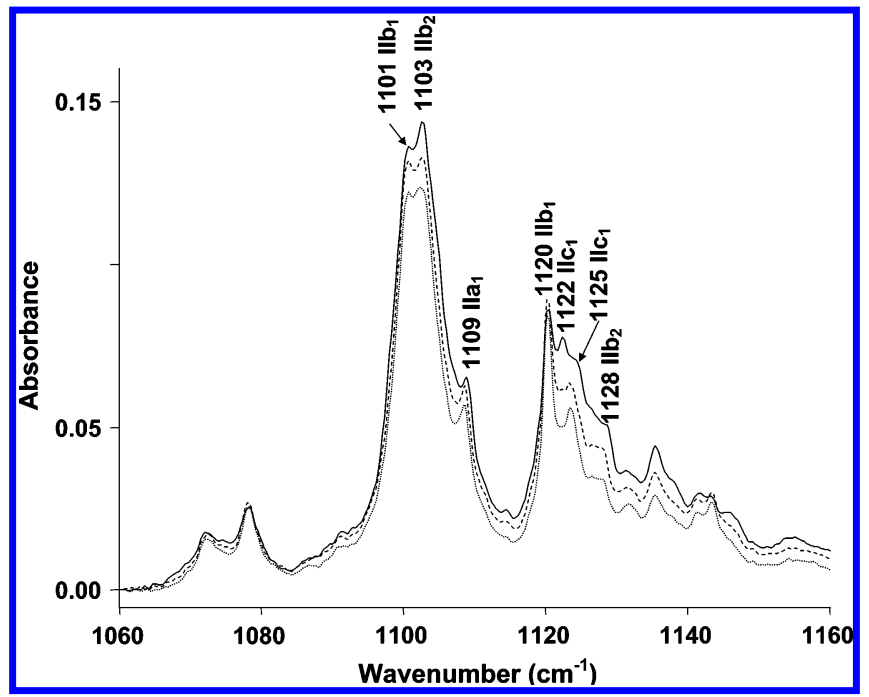

Figure 5. Comparison of the Phe spectra obtained immediately after deposition at $12 \mathrm{~K}$ (solid line) with the spectra of Phe matrix annealed to 24 and $27 \mathrm{~K}$ (dashed and dotted line, respectively) in the 1060$1160 \mathrm{~cm}^{-1}$ range.

$\mathrm{K}$ followed by its decrease at $27 \mathrm{~K}$, whereas all the remaining absorptions continuously decrease in intensity with temperature, though at different rates (Figure 5).

The observed decrease in intensity with temperature is the most prominent in the case of the group of bands in the 1122$1128 \mathrm{~cm}^{-1}$ range, less significant for the band at $1103 \mathrm{~cm}^{-1}$ and even weaker for the bands at 1101,1109 and $1120 \mathrm{~cm}^{-1}$. This qualitative description (quantitative measurements cannot be made because of strong band overlap) along with the results of the calculations allows us to explain the observations and assign the bands. Therefore, the absorbances showing the smallest decrease in intensity are related to the conformers in this group that have stronger intramolecular $\mathrm{H}$-bond interactions, i.e., $\mathrm{IIa}_{1}$ and $\mathrm{IIb}_{1}$, which should show the weaker ability to aggregate. Therefore, the band at $1101 \mathrm{~cm}^{-1}$ is assigned to the mixed $v(\mathrm{C}-\mathrm{N}) / v(\mathrm{C}-\mathrm{O})$ stretching vibration of conformer IIb 1 (calc: $\left.1095 \mathrm{~cm}^{-1}\right)$, the absorption at $1109 \mathrm{~cm}^{-1}$ to the $\nu(\mathrm{C}-\mathrm{O}) / \delta(\mathrm{C}-\mathrm{O}-\mathrm{H})$ mode of $\mathrm{IIa}_{1}\left(\right.$ calc: $\left.1097 \mathrm{~cm}^{-1}\right)$ and the band at $1120 \mathrm{~cm}^{-1}$ to the highly delocalized vibration of $\mathrm{IIb}_{1}$ containing contributions from $v(\mathrm{C}-\mathrm{O}), \delta(\mathrm{C}-\mathrm{O}-\mathrm{H})$ and $\alpha$-hydrogen $\left(\mathrm{H}_{6}\right)$ bending internal coordinates (calc: $1121 \mathrm{~cm}^{-1}$ ). The latter band should also have a minor contribution from the band of $\mathrm{IIa}_{1}$ predicted at $1120 \mathrm{~cm}^{-1}$ [predominantly $\delta(\mathrm{N}-\mathrm{C}-\mathrm{H})$ and $\left.\delta\left(\mathrm{C}_{10}-\mathrm{C}_{5}-\mathrm{H}_{6}\right)\right]$. On the other hand, the band at $1103 \mathrm{~cm}^{-1}$ and the shoulder at $1128 \mathrm{~cm}^{-1}$ can be correlated with the vibrations of conformer $\mathrm{IIb}_{2}$ calculated at $1097 \mathrm{~cm}^{-1}$ [mainly $v(\mathrm{C}-\mathrm{O})]$ and $1123 \mathrm{~cm}^{-1}[v(\mathrm{C}-\mathrm{N})]$, respectively. Finally, conformer $\mathrm{IIc}_{1}$, which has a significantly weaker intramolecular H-bond (see Table 2), should tend to associate more easily and, accordingly, the bands it originates correspond to those that decrease more after annealing. In this spectral range, there are two bands, at 1122 and $1225 \mathrm{~cm}^{-1}$, which strongly decline after annealing. At the highest temperatures reached, these two bands merge into a single band at $1124 \mathrm{~cm}^{-1}$. Thus, they were assigned to the $v(\mathrm{C}-\mathrm{O}) / \delta(\mathrm{C}-\mathrm{O}-\mathrm{H})$ site-split absorption of $\mathrm{IIc}_{1}$.

$C=O$ Stretching Region. The bands at 1768 [calc: $1764 \mathrm{~cm}^{-1}$ $\left(\mathrm{IIc}_{1}\right)$ ], 1770 [calc: $\left.1768 \mathrm{~cm}^{-1}\left(\mathrm{IIb}_{2}\right)\right], 1775$ [calc: $1774 \mathrm{~cm}^{-1}$ $\left(\mathrm{IIa}_{1}\right)$ ], 1778 [shoulder, calc: $1778 \mathrm{~cm}^{-1}\left(\mathrm{IIb}_{1}\right)$ ], 1789 [calc: $1791 \mathrm{~cm}^{-1}$ (Ia)] and 1793 [shoulder, calc: $1799 \mathrm{~cm}^{-1}\left(\mathrm{Ib}_{1}\right)$ ] $\mathrm{cm}^{-1}$ are assigned to nearly unperturbed $\mathrm{C}=\mathrm{O}$ stretching vibrations. Although usually $v(\mathrm{C}=\mathrm{O})$ bands are highly diag-

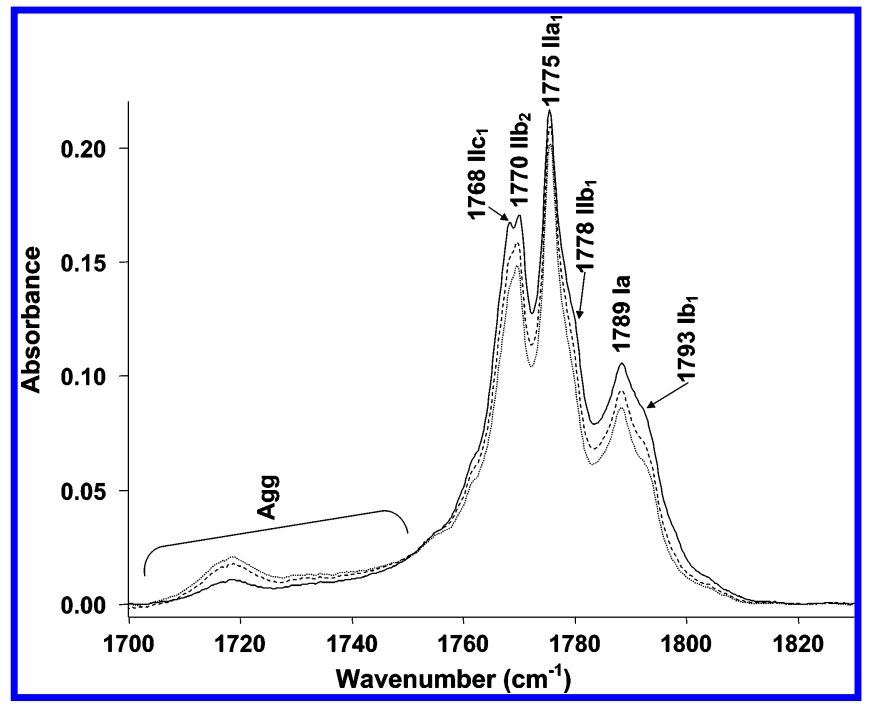

Figure 6. Comparison of the Phe spectra obtained immediately after deposition at $12 \mathrm{~K}$ (solid line) with the spectra of Phe matrix annealed to 24 and $27 \mathrm{~K}$ (dashed and dotted line, respectively) in the 1700$1830 \mathrm{~cm}^{-1}$ range.

nostic, in the Phe case they are strongly superimposed (see Figure 3), which complicates their assignment to each conformer. Despite being tentative, the following general conclusions can be made: (i) the $v(\mathrm{C}=\mathrm{O})$ absorptions due to conformers of type II are observed at lower wavenumbers than the bands originating from type I conformers, due to the involvement of the $\mathrm{C}=\mathrm{O}$ group in intramolecular hydrogen bonding in the conformers of the former type; (ii) however, because the differences between the observed $v(\mathrm{C}=\mathrm{O})$ frequencies in conformers of type II and I are small, these H-bonds are weak, pointing once again to the importance of other factors (as steric factors mentioned above) in determining the relative energy of the conformers; (iii) the tendency of conformers to aggregate increases in the order: $\mathrm{IIa}_{1} \approx \mathrm{IIb}_{1}<\mathrm{IIb}_{2} \approx \mathrm{Ia} \approx$ $\mathrm{Ib}_{1}<\mathrm{IIc}_{1}$ (cf. Figure 6). Aggregation results in increase, upon annealing of the sample, of the very broad band centered at ca. $1719 \mathrm{~cm}^{-1}$.

$O-H$ and $N-H$ Stretching Region. In the $3100-3600 \mathrm{~cm}^{-1}$ range (see Figure 4) the bands due to $\mathrm{O}-\mathrm{H}$ and $\mathrm{N}-\mathrm{H}$ stretching vibrations are observed. As mentioned above, the anharmonicity of these vibrations results in the worse agreement of the experimental and calculated spectra in this range.

The $\mathrm{N}-\mathrm{H}$ stretching modes are seen in the spectra as two broad bands of quite low intensity, centered at $\sim 3340$ and 3410 $\mathrm{cm}^{-1}$. The absorptions associated with the $\mathrm{O}-\mathrm{H}$ stretchings of type I conformers are observed at lower wavenumbers than in type II forms, due to the participation of the $\mathrm{O}-\mathrm{H}$ group in the $\mathrm{O}-\mathrm{H} \cdots \mathrm{N}$ H-bond. The broad band centered at $\sim 3178 \mathrm{~cm}^{-1}$ is then assigned to the $v(\mathrm{O}-\mathrm{H})$ vibrations of conformers $\mathrm{Ib}_{1}$ and Ia [calc.: $3388 \mathrm{~cm}^{-1}$ (Ia) and $3409 \mathrm{~cm}^{-1}\left(\mathrm{Ib}_{1}\right)$ ]. On the other hand, the calculations predicted the bands associated with free $\mathrm{O}-\mathrm{H}$ stretches in $\mathrm{IIc}_{1}, \mathrm{IIb}_{2}, \mathrm{IIa}_{1}$ and $\mathrm{IIb}_{1}$ forms at 3665, 3673, 3678 and $3679 \mathrm{~cm}^{-1}$, respectively, which are ascribed to four partially superimposed bands at $3557 \mathrm{~cm}^{-1}$ (IIc 1 and $\mathrm{IIb}_{2}$ ), 3559 $\mathrm{cm}^{-1}\left(\mathrm{IIa}_{1}\right)$ and $3562,3567 \mathrm{~cm}^{-1}\left(\mathrm{IIb}_{1}\right)$ in the experimental spectrum, as discussed in detail below. Note that the bands associated with the $\mathrm{O}-\mathrm{H}$ stretching vibrations were observed at nearly the same wavenumbers in the spectrum of monomeric serine. ${ }^{27}$ For that compound, the conformer with the free $\mathrm{O}-\mathrm{H}$ group was shown to give rise to a band at $3567 \mathrm{~cm}^{-1}$, whereas the $\mathrm{O}-\mathrm{H}$ stretching in the conformers bearing the $\mathrm{O}-\mathrm{H} \cdots \mathrm{N}$ hydrogen bond were considered to give rise to the very broad 


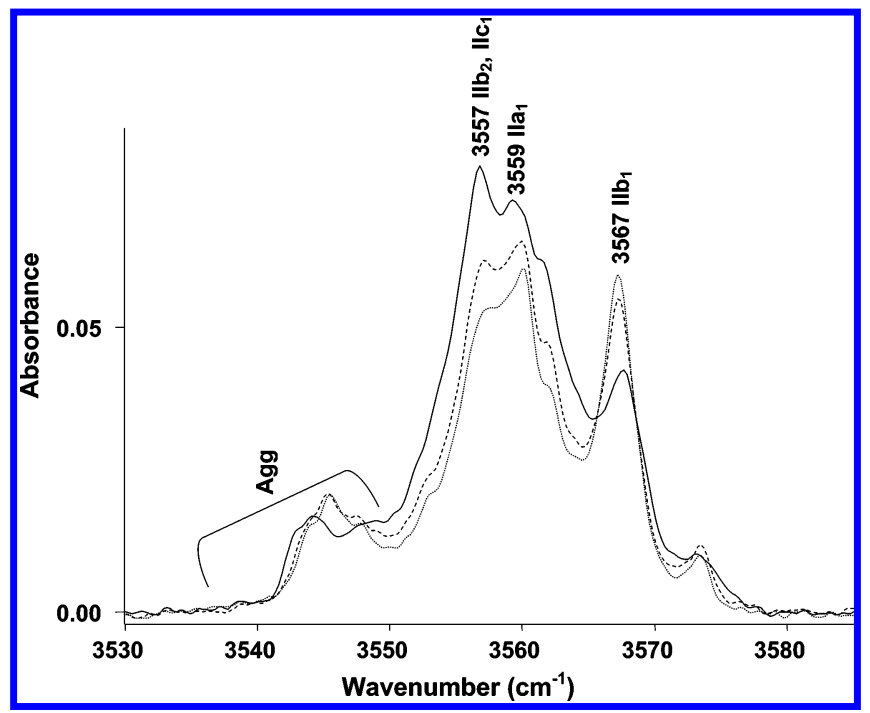

Figure 7. Comparison of the Phe spectra obtained immediately after deposition at $12 \mathrm{~K}$ (solid line) with the spectra of Phe matrix annealed to 24 and $27 \mathrm{~K}$ (dashed and dotted line, respectively) in the 3530$3590 \mathrm{~cm}^{-1}$ range.

band at ca. $3170 \mathrm{~cm}^{-1} .{ }^{27}$ Similar results were also previously reported for aliphatic amino acids such as, for example, glycine, ${ }^{17}$ alanine ${ }^{22}$ and valine. ${ }^{24}$

As a result of annealing of the matrix, the bands assigned to the $v(\mathrm{O}-\mathrm{H})$ stretching mode of conformers of type II show a clear distinct pattern of variation. The bands at 3557, 3559 and $3562 \mathrm{~cm}^{-1}$ decrease in intensity, whereas the band centered at $3567 \mathrm{~cm}^{-1}$ increases to $27 \mathrm{~K}$ (cf., Figure 7). On the basis of the calculations, the intense feature at $3557 \mathrm{~cm}^{-1}$ may be attributed to both forms $\mathrm{IIb}_{2}$ and $\mathrm{IIc}_{1}$ (calc: 3673 and $3665 \mathrm{~cm}^{-1}$, respectively), which is in consonance with the significant decrease in intensity observed for this band upon annealing. The assignment of the bands at 3559 and 3562 and $3568 \mathrm{~cm}^{-1}$ is more tentative. The first is assigned to conformer $\mathrm{IIa}_{1}$ (calc: $3678 \mathrm{~cm}^{-1}$ ) because it decreases in intensity less than the band at $3557 \mathrm{~cm}^{-1}$. Additionally, the fact that the center of the band shifts after annealing (to $\sim 3559 \mathrm{~cm}^{-1}$ ), suggests that this band might be just one component of a site-split feature originating from the $\mathrm{O}-\mathrm{H}$ group of $\mathrm{IIa}_{1}$ whose additional components are buried within the complex profile observed in this spectral region. The bands observed at 3562 and $3567 \mathrm{~cm}^{-1}$ are assigned to conformer $\mathrm{IIb}_{1}$. Both absorptions shift after annealing $(\sim 1$ $\mathrm{cm}^{-1}$ toward higher and lower wavenumbers, respectively) and, additionally, one of them $\left(3568 \mathrm{~cm}^{-1}\right)$ significantly increases its intensity while the other declines. Therefore, these two bands shall originate in molecules of conformer $\mathrm{IIb}_{1}$ occupying matrix sites where the corresponding $\mathrm{OH}$ moieties interact in a different way with the matrix. Annealing of the matrix promotes one of them at the expense of the other. Finally, the broad band at $3544 \mathrm{~cm}^{-1}$, which continuously grows upon annealing, is, with all probability, due to aggregates of the compound.

3.4. Photolysis of Matrix-Isolated Phe. Upon photolysis $(\lambda>235 \mathrm{~nm})$ of Phe, a gradual increase of intensity of the bands assigned to carbon dioxide was observed (after $30 \mathrm{~min}$ and ca. $3 \mathrm{~h}$ ) with a simultaneous decrease of intensity of the absorptions due to the compound. The antisymmetric stretching vibration of carbon dioxide, at $\sim 2340 \mathrm{~cm}^{-1}$, is strongly broadened, suggesting that the photoproduced $\mathrm{CO}_{2}$ does not diffuse out of the cage but rather is associated with the other photoproduct(s).

Phenethylamine appears as the most plausible species produced upon decarboxylation of Phe, together with $\mathrm{CO}_{2}$. In the vapor phase, nine major absorptions of phenethylamine are observed at 3037 (m), 2943 (s), 2860 (m), 1613 (m), 1500 (m), $1454(\mathrm{~m}), 1075(\mathrm{~m}), 744(\mathrm{~s})$ and $699(\mathrm{~s}) .{ }^{55}$ However, in the spectrum of the irradiated Phe matrix, the majority of bands at such wavenumbers should be strongly overlapped with the Phe absorptions (namely bands at 3037, 1613, 1500, 1454, 744 and $699 \mathrm{~cm}^{-1}$ ). Therefore, only two new absorptions that can be assigned to phenethylamine vibrations are observed, at 748 and $2945 \mathrm{~cm}^{-1}$, in the spectrum of the irradiated matrix. Definitive identification of phenethylamine as photoproduct of decarboxylation of matrix-isolated Phe should still deserve further attention in the future. However, the fact that the UV-stimulated decarboxylation of matrix-isolated serine, under similar experimental conditions, has been found to yield ethanolamine, ${ }^{27}$ strongly reinforces the proposed interpretation.

\section{Conclusions}

The IR spectrum of Phe isolated in low-temperature solid argon was obtained for the first time. The conformational behavior of the compound isolated in the matrix was studied on the basis of annealing experiments for the matrix-isolated substance, supported by B3LYP/6-311++G(d,p) calculations.

Eight conformers with abundances higher than $5 \%$ were predicted by the calculations to exist at the temperature of sublimation of the compound $(423.15 \mathrm{~K})\left(\mathrm{Ib}_{1}, \mathrm{Ia}_{1} \mathrm{IIa}_{1}, \mathrm{IIb}_{1}, \mathrm{IIb}_{2}\right.$, $\mathrm{IIc}_{1}, \mathrm{IIb}_{3}$ and IIIb 3 , cf., Figure 1). However, no bands associated with conformers $\mathrm{Ilb}_{3}$ and $\mathrm{IIIb}_{3}$ were observed in the experimental spectrum, indicating that these two conformers relax to a more stable form during deposition of the matrix. This result is consistent with the low predicted energy barriers for the $\mathrm{IIb}_{3} \rightarrow \mathrm{IIb}_{2}\left(0.92 \mathrm{~kJ} \mathrm{~mol}^{-1}\right)$ and $\mathrm{IIIb}_{3} \rightarrow \mathrm{IIb}_{2}\left(2.16 \mathrm{~kJ} \mathrm{~mol}^{-1}\right)$ conversions.

The lowest-energy conformers of Phe ( $\mathrm{Ib}_{1}$ and Ia) differ only in the arrangement of the amino acid group with respect to the phenyl ring and are stabilized by a relatively strong $\mathrm{O}-\mathrm{H} \cdots \mathrm{N}$ intramolecular hydrogen bond, while destabilized by the trans conformation of the carboxylic group. The strong $\mathrm{O}-\mathrm{H} \cdots \mathrm{N}$ bond in conformers of type I provides their enthalpic stabilization relative to type II conformers, which bear the much weaker $\mathrm{N}-\mathrm{H} \cdots \mathrm{O}(=\mathrm{C})$ hydrogen bond. However, entropic factors associated with $\mathrm{H}$-bond strengths and steric hindrance point to the opposite direction, decreasing the relative abundances of forms Ia and Ib at higher temperatures. Indeed, the obtained results show that entropy effects may be essential to determine the relative abundance of different amino acid conformers having close energies and different steric hindrance or intramolecular H-bond strengths.

The photolysis of Phe upon UV irradiation resulted in decarboxylation of the compound, probably bringing phenethylamine as the accompanying product of this reaction.

Acknowledgment. We are grateful to the referees for their valuable comments and suggestions. Calculations were done at the Academic Computer Center "Cyfronet", Krakow, Poland, and The Interdisciplinary Center for Mathematical and Computational Modeling, Warsaw University, Warsaw, Poland, which are acknowledged for computing time. The research was supported by the Portuguese Fundação para a Ciência e a Tecnologia (Grants FCT \#SFRH/BPD/17081/2004, SFRH/BPD/ 1661/2000, POCTI/QUI/58937/2005 and POCTI/QUI/59019/ 2005, also supported by FEDER).

Supporting Information Available: Tables giving the definition of the internal coordinates used in the normal mode 
analysis of Phe and assignments of the experimental spectrum of Phe in an Ar matrix. This material is available free of charge via the Internet at http://pubs.acs.org.

\section{References and Notes}

(1) Almlöf, J.; Kvick, A.; Thomas, J. O. J. Chem. Phys. 1973, 59, 3901 (2) Simpson, H. J., Jr.; Marsh, R. E. Acta Crystallogr. 1966, 20, 550.

(3) Freedman, T. B.; Diem, M.; Polavarapu, P. L.; Nafie, L. A. J. Am. Chem. Soc. 1982, 104, 3343.

(4) Iijima, K.; Tanaka, K.; Onuma, S. J. Mol. Struct. 1991, 246, 257. (5) Godfrey, P. D.; Brown, R. T.; Rodgers, F. M. J. Mol. Struct. 1996, 376,65 .

(6) Blanco, S.; Lessari, A.; López, J. C.; Alonso, J. L. J. Am. Chem. Soc. 2004, 126, 11675.

(7) Lessari, A.; Cocinero, E. J.; López, J. C.; Alonso, J. L. Angew. Chem., Int. Ed. 2004, 43, 605.

(8) Lessari, A.; Mata, S.; Cocinero, J.; Blanco, S.; López, J. C.; Alonso, J. L. Angew. Chem., Int. Ed. 2002, 41, 6473.

(9) Snoek, L. C.; Robertson, E. G.; Kroemer, R. T.; Simons, J. P. Chem. Phvs. Lett. 2000, 321, 49.

(10) Lee, K. T.; Sung, J.; Lee, K. J.; Kim, S. K.; Park, J. D. J. Chem. Phvs. 2002, 116, 8251.

(11) Lee, Y.; Jung, J.; Kim, B.; Butz, P.; Snoek, L. C.; Kroemer, R. T.; Simons, J. P. J. Phys. Chem. A 2004, 108, 69.

(12) Snoek, L. C.; Kroemer, R. T.; Hockridge, M. R.; Simons, J. P. Phys. Chem. Chem. Phys. 2001, 3, 1819.

(13) Bakker, J. M.; Aleese, L. M.; Meijer, G.; von Helden, G. Phvs. Rev. Lett. 2003, 91, 203003-1.

(14) Grenie, Y.; Lassegues, J.-C.; Garrigou-Lagrange, C. J. Chem. Phvs. 1970, 53, 2980.

(15) Reva, I. D.; Plokhotniczenko, A. M.; Stepanian, S. G.; Ivanov, A. Yu.; Radchenko, E. D.; Sheina, G. G.; Blagoi, Yu. P. Chem. Phvs. Lett. 1995, 232, 141. Erratum. Chem. Phvs. Lett. 1995, 235, 617.

(16) Ivanov, A. Yu.; Sheina, G. G.; Blagoi, Yu. P. Spectrochim. Acta A 1999, 55,219

(17) Stepanian, S. G.; Reva, I. D.; Radchenko, E. D.; Rosado, M. T. S.; Duarte, M. L. T. S.; Fausto, R.; Adamowicz, L. J. Phys. Chem. A 1998, 102,1041 .

(18) Huisken, F.; Werhahn, O.; Ivanov, A. Yu.; Krasnokutski, S. A. J. Chem. Phvs. 1999, 111, 2978.

(19) Gómez-Zavaglia, A.; Fausto, R. Vibr. Spectrosc. 2003, 33, 105.

(20) Gómez-Zavaglia, A.; Reva, I. D.; Fausto, R. Phvs. Chem. Chem. Phys. 2003, 5, 41

(21) Rosado, M. T. S.; Duarte, M. L. T. S.; Fausto, R. J. Mol. Struct. 1997, 410-411, 343

(22) Stepanian, S. G.; Reva, I. D.; Radchenko, E. D.; Adamowicz, L. J. Phvs. Chem. A 1998, 102, 4623.

(23) Lambie, B.; Ramaekers, R.; Maes, G. Spectrochim. Acta A 2003 $59,1387$.

(24) Stepanian, S. G.; Reva, I. D.; Radchenko, E. D.; Adamowicz, L. J. Phvs. Chem. A 1999, 103, 4404.

(25) Reva, I. D.; Stepanian, S. G.; Plokhotnichenko, A. M.; Radchenko, E. D.; Sheina, G. G.; Blagoi, Yu. P. J. Mol. Struct. 1994, 318, 1.

(26) Stepanian, S. G.; Reva, I. D.; Radchenko, E. D.; Adamowicz, L. J. Phys. Chem. A 2001, 105, 10664.

(27) Jarmelo, S.; Lapinski, L.; Nowak, M.; Carey, P. R.; Fausto, R. J. Phvs. Chem. A 2005, 109, 5689.

(28) Lambie, B.; Ramaekers, R.; Maes, G. J. Phvs. Chem. A, 2004, 108 10426

(29) Rizzo, T. R.; Park, Y. D.; Peteanu L. A.; Levy, D. H. J. Chem. Phvs. 1986, 84, 2534.

(30) Martinez, S. J., III; Alfano, J. C.; Levy, D. H. J. Mol. Spectrosc. 1992, 156, 421

(31) Bakker, J. M.; Aleese, L. M.; Meijer G.; von Helden, G. Phys. Rev. Lett. 2003, 91, 203003-1.

(32) Lee, K. T.; Sung, J.; Lee, K. J.; Kim, S. K.; Park, Y. D. Chem. Phvs. Lett. 2003, 368, 262.
(33) Linder, R.; Nispel, M.; Häber, T.; Kleinermanns, K. Chem. Phvs. Lett. 2005, 409, 260.

(34) Ramaekers, R.; Pajak, J.; Rospenk, M.; Maes, G. Spectrochim. Acta A 2005, 61, 1347 .

(35) Becke, A. D. Phys. Rev. A 1988, 38, 3098.

(36) Lee, C. T.; Yang, W. T.; Parr, R. G. Phvs. Rev. B 1988, 37, 785.

(37) Reva, I. D.; Jarmelo, S.; Lapinski, L.; Fausto, R. J. Phvs. Chem. A 2004, 108, 6982 .

(38) Frisch, M. J.; Trucks, G. W.; Schlegel, H. B.; Scuseria, G. E.; Robb M. A.; Cheeseman, J. R.; Zakrzewski, V. G.; Montgomery, J. A., Jr. Stratmann, R. E.; Burant, J. C.; Dapprich, S.; Millam, J. M.; Daniels, A. D.; Kudin, K. N.; Strain, M. C.; Farkas, O.; Tomasi, J.; Barone, V.; Cossi, M.; Cammi, R.; Mennucci, B.; Pomelli, C.; Adamo, C.; Clifford, S. Ochterski, J.; Petersson, G. A.; Ayala, P. Y.; Cui, Q.; Morokuma, K.; Rega, N.; Salvador, P.; Dannenberg, J. J.; Malick, D. K.; Rabuck, A. D.; Raghavachari, K.; Foresman, J. B.; Cioslowski, J.; Ortiz, J. V.; Baboul, A. G.; Stefanov, B. B.; Liu, G.; Liashenko, A.; Piskorz, P.; Komaromi, I.; Gomperts, R.; Martin, R. L.; Fox, D. J.; Keith, T.; Al-Laham, M. A.; Peng, C. Y.; Nanayakkara, A.; Challacombe, M.; Gill, P. M. W.; Johnson, B.; Chen, W.; Wong, M. W.; Andres, J. L.; Gonzalez, C.; Head-Gordon, M.; Replogle, E. S.; Pople, J. A. Gaussian 98, revision A.11.4; Gaussian, Inc.: Pittsburgh, PA, 2002.

(39) Frisch, M. J.; Trucks, G. W.; Schlegel, H. B.; Scuseria, G. E.; Robb, M. A.; Cheeseman, J. R.; Montgomery, J. A., Jr.; Vreven, T.; Kudin, K. N.; Burant, J. C.; Millam, J. M.; Iyengar, S. S.; Tomasi, J.; Barone, V.; Mennucci, B.; Cossi, M.; Scalmani, G.; Rega, N.; Petersson, G. A.; Nakatsuji, H.; Hada, M.; Ehara, M.; Toyota, K.; Fukuda, R.; Hasegawa, J.; Ishida, M.; Nakajima, T.; Honda, Y.; Kitao, O.; Nakai, H.; Klene, M.; Li, X.; Knox, J. E.; Hratchian, H. P.; Cross, J. B.; Adamo, C.; Jaramillo, J.; Gomperts, R.; Stratmann, R. E.; Yazyev, O.; Austin, A. J.; Cammi, R.; Pomelli, C.; Ochterski, J. W.; Ayala, P. Y.; Morokuma, K.; Voth, G. A.; Salvador, P.; Dannenberg, J. J.; Zakrzewski, V. G.; Dapprich, S.; Daniels, A. D.; Strain, M. C.; Farkas, O.; Malick, D. K.; Rabuck, A. D.; Raghavachari, K.; Foresman, J. B.; Ortiz, J. V.; Cui, Q.; Baboul, A. G.; Clifford, S.; Cioslowski, J.; Stefanov, B. B.; Liu, G.; Liashenko, A.; Piskorz, P.; Komaromi, I.; Martin, R. L.; Fox, D. J.; Keith, T.; Al-Laham, M. A.; Peng, C. Y.; Nanayakkara, A.; Challacombe, M.; Gill, P. M. W.; Johnson, B.; Chen, W.; Wong, M. W.; Gonzalez, C.; Pople, J. A. Gaussian 03, revision C.02; Gaussian, Inc.: Wallingford, CT, 2004

(40) Pulay, P.; Fogarasi, G.; Pang F.; Boggs, J. E. J. Am. Chem. Soc. 1979, 101, 2550.

(41) Martin, J. M. L.; Van Alsenoy, C. Gar2ped, University of Antwerp, 1995.

(42) Joela, H.; Mustafi, D.; Fair, C. C.; Makinen, M. W. J. Phvs. Chem 1991, 95, 9135.

(43) Duan, G. L.; Smith, V. H., Jr.; Weaver, D. F. Int. J. Ouantum Chem. 2002, 90, 669

(44) Jakli, I.; Perczel, A.; Farkas, O.; Hollosi, M.; Csizmadia, I. G. J. Mol. Struct. (THEOCHEM) 1998, 455, 303.

(45) Csaszar, A. G.; Perczel, A. Prog. Biophys. Mol. Biol. 1999, 71 243.

(46) Avbelj, F.; Fele, L. J. Mol. Biol. 1998, 279, 665.

(47) Doig, A. J. Biophys. Chem. 1996, 61, 131.

(48) Ruoff, R. S.; Klots, T. D.; Emilsson T.; Gutowsky, H. S. J. Chem. Phvs. 1990, 93, 3142

(49) Reva, I. D.; Ilieva S. V.; Fausto, R. Phvs. Chem. Chem. Phvs. 2001 3,4235 .

(50) Reva, I. D.; Stepanian, S. G.; Adamowicz, L.; Fausto, R. Chem. Phys. Lett. 2003, 374, 631

(51) Michaut, X.; Vasserot, A. M.; Abouaf-Marguin, L. Vibr. Spectrosc 2004, 34, 83 .

(52) Gómez-Zavaglia, A.; Reva, I. D.; Frija, L.; Cristiano, M. L.; Fausto, R. J. Phvs. Chem. A 2005, 109, 7967.

(53) Lopes, S.; Gómez-Zavaglia, A.; Lapinski, L.; Fausto, R. J. Phvs. Chem. A 2005, 109, 5560.

(54) Andrzejewska, A.; Lapinski, L.; Reva, I. D.; Fausto, R. Phvs. Chem. Chem. Phvs. 2002, 4, 3289

(55) Choi, Y.; Lubman, D. M. Anal. Chem. 1992, 64, 2726. 